\title{
L'INSTITUTION DE LA MAJESTÉ* *
}

\author{
LA MAJESTÉ DES INSTITUTIONS
}

Au temps de la République romaine, la Majesté avait commencé par désigner l'état de supériorité d'une institution par rapport à d'autres. Supériorité relative plutôt que supériorité absolue, comme l'indique assez clairement la formation du vocable : la maiestas d'un être est au sens propre sa qualité, son statut de maior. Elle implique naturellement l'existence d'autres êtres jugés minores par rapport à lui ${ }^{1}$. Elle suppose une organisation hiérarchique de la réalité institutionnelle. C'est pourquoi, en de nombreux textes latins, elle va de pair avec la « dignité », expression morale du rang qui distingue les titulaires de charges publiques, magis-

* Cet article est la première version d'un chapitre du livre que prépare Yan Thomas, en collaboration avec Jacques Chiffoleau, sur le crime de Lèse-Majesté de ses origines romaines au xvir siècle.

Les revues et publications sont citées selon les abréviations en usage dans l'Année philologique. Les sources littéraires latines apparaissent en principe sous les formes abrégées couramment admises.

Abréviations de corpus documentaires :

CIL Corpus Inscriptionum Latinarum

CJ Codex Justinianus

CSEL Corpus Scriptorum Eccleciasticorum Latinorum

$D$ Digeste

ILLRP A. Degrassi, Inscriptiones Latinae Liberae Republicae

ILS H. Dessau, Inscriptiones Latinae Selectae

1. G. DumeziL, « Maiestas et gravitas », in Idées romaines, Paris, 1969, p. 123-152, qui tire parti de l'expression pro maiestate, "à proportion du rang supérieur » tenu par l'un des deux termes d'une comparaison (VIRGILE, Enéide, 12, v. 820 sq. LuCRËCE, De natura rerum, 5, v. 2). Sur l'idée juridique de prééminence, voir T. Mommsen, Droit pénal romain, II, $2^{\circ}$ éd. Paris, de Boccard, 1984, p. 234 sq. ; E. Pollack, Der Majestätsgedanke im römischen Recht, Leipzig, 1908; B. KÜBleR, s.v. " Maiestas ", Realenzyklopädie, 14, c. 542 sq. Contre toute évidence, A. N. SHERWIN-WHIIE réfute la valeur comparative du mot : c.r. de R. A. BAUMAN, cité infra n. 16, Gnomon, 1969, p. 289. À propos du crime de majesté, Isidore, Etymologies, 10,238 , transmet une excellente glose étymologique : "quia maius est laedere patriam quam civem unum."

Revue de synthèse : IV S. Nos 3-4, juil.-déc. 1991. 
trats et sénateurs, ou les Romains comparés aux autres cités, ou la cité confrontée aux citoyens pris individuellement - en sorte que l'ordre de dignatio à l'intérieur d'un collège public, par exemple, est à proportion des « distinctions de majesté ", discrimina maiestatis, qui séparent ses divers degrés ; et qu'une « diminution de majesté », deminutio maiestatis, peut se définir comme une dégradation, comme une privation de digni$t^{2}{ }^{2}$. On la trouve associée aussi à l'auctoritas, laquelle pèse à l'intérieur d'une relation par hypothèse inégale; ou encore à la gravitas, qualité de ce qui l'emporte en poids ${ }^{3}$.

Selon une allégorie brillamment développée dans les Fastes d'Ovide, unique passage de la littérature latine où nous la voyons naître et agir sous la forme d'une abstraction personnifiée, Maiestas émerge du Chaos comme institution de la distance politique : elle était absente du monde tant que " tous les degrés d'honneur étaient égaux » et dut attendre pour être engendrée que Rang et Révérence - Honos et Reverentia - eussent " soumis leurs corps aux obligations d'une couche légitime ». Pudeur et Crainte - Pudor et Metus - prennent place à ses côtés lorsqu'elle siège,

2. Relation entre degré du rang et discrimina maiestatis : FEstus, p. 144 L. Dans un tout autre contexte, cette expression me parait trouver un équivalent dans le " tertium gradum maiestatis » dont parle Tertullien à propos de l'Esprit Saint (Adversus Praxean, 11, 9 = CSEL, 5, 244). À noter également, chez Trte-Live, 3, 63, 10, l'expression d'une majesté propre à chaque ordre : « si chaque ordre conserve ses propres droits et sa propre majesté, si sua quisque iura ordo, suam maiestatem teneat."

M. et dignitas : Rhetor. ad Herennium, 4, 35 ( $m$. = " rang et grandeur ", dignitas et amplitudo); CiCERON, De inventione, 2,53 ( $~(\mathrm{~m}$. minuere " = " retirer quelque chose au rang - dignitas - et à la grandeur du peuple Romain "; De oratore, 2, 164 ; Partitiones oratoriae, 105 (m. = "l'empire et le rang - imperium atque dignitas - du nom romain "); $A d$ Quirites, 4. Clause formulaire « le rang et la majesté du peuple Romain » dans les actes officiels : lex Gabinia Calpurnia de Délos, $C I L, 1,2,2500.18$. D. et m. des consuls : CicÉron, In Pisonem, 24 et Philippiques, 13, 20; cf. TIte-Live, 42, 49, 1. Sur cette association, voir H. Wegehaup, Die Bedeutung und Anwendung von dignitas in den Schriften der republikanischen Zeit, Breslau, 1932, p. 62 et 77 et J. HellegouAR'CH, Le Vocabulaire latin des relations et des partis politiques, Paris, 1972, p. 402. Sur la valeur comparative et hiérarchique de dignitas, C. Nicolet, L'Ordre équestre à l'époque républicaine, Ec. Fr. Rome, 1974, p. 236 sq.

3. M. et auctoritas : Varron, Res nusticae, 2, 5, 3-4; CICEron, Divinatio in Caecilium, 69, « l'autorité de l'empire et la majesté de la cité "; Sutrone, Vespasien, 2 (où une « auctoritas et quasi maiestas quaedam " est reconnue à Vitellius). Les deux notions sont parfois opposées, à l'époque républicaine, lorsqu'il s'agit de distinguer les compétences juridiques du Sénat et du Peuple : ainsi, CicÉron, Philippiques, 3, 13, cf. G. H. Gundel, « Der Begriff Maiestas im politischen Denken der römischen Republik ", Historia, 12, 1963, p. 300, et Pro Sestio, 83; dans pro Rabirio perd. reo, 2, l'auctoritas du sénat et le pouvoir des magistrats sont distingués de la maiestas de la res publica tout entière (texte que Bodin tirait du côté de la souveraineté du peuple en le citant d'une manière déformée : "imperium in magistratibus, auctoritatem in senatu, potestatem in plebe, maiestatem in populo": République, L. 1, chap. 10, "Des vrayes marques de Souveraineté »). Sous l'Antiquité tardive, on combinera les deux concepts en formulant une " autorité de la majesté " (références in GUNDEL, loc. cit., n. 4). vis ".

M. et gravitas : Trte-Live, 5, 41, 8; 45, 40, 4 et Cicéron, Div. in Caec., 69, " maiestas gra- 
revêtue de pourpre et d'or, pour assurer l'observation des prérogatives et le respect des rangs ${ }^{4}$. Tel lexicographe de la fin de la République, dans cet esprit, concevait l'ordre hiérarchique, du plus haut jusqu'au plus bas, comme une suite de "distinctions de majesté ». Tel juriste du premier siècle de notre ère, dans les mêmes termes que Cicéron un siècle plus tôt, glosait sur la cause de majesté inscrite dans les traités inégaux par ces mots : « être dans une position supérieure ». Et c'est encore d'après ce modèle que le grammairien Charisius construisait une série d'analogies depuis « honneur » et « rang », honor et honos, jusqu'à « grandeur » et « majesté » en passant par « noblesse ", « dignité », « autorité », " ampleur », « illustration ", « éclat " ${ }^{5}$.

La position de majesté implique une échelle de grandeurs comparées : prérogative des magistrats sur le peuple ou du peuple sur les magistrats, supériorité d'une cité sur d'autres, excellence des grands hommes au regard de ceux du commun. Elle définit même le niveau le plus élevé de la hiérarchie, le sommet qui culmine par-dessus tout le reste, unique en son éminence : ainsi la majesté de Rome sur le reste du monde ou, sous l'Empire, la majesté du prince monarque et bientôt, avec le christianisme, par une élévation incommensurable du lieu de la transcendance et par un déplacement de la référence politique ultime vers le haut, la majesté de Dieu. La qualité de maior passe alors, selon l'analyse de G. Dumézil, du comparatif au superlatif. La distance qui sépare des autres l'être qui la possède est poussée à l'extrême. Elle s'applique maintenant à un terme dont la contrepartie est tout le reste : l'instance ultime est son lieu propre. Dans cette disposition souveraine, pourtant, la notion reste accrochée au degré moyen. À quelque niveau où se situent les êtres qu'elle exhausse, l'expression abstraite de ce qui les grandit n'indique rien de plus qu'une inégalité relative. C'est toujours à partir de maior, jamais sur maximus; qu'est pensé l'état de ce qui est parvenu au faîte de la hauteur, même si cet état, défini substantivement par le comparatif, est qualifié adjectivement par le superlatif : maiestas du magistrat en position suprême et qualifié pour cela de maximus; maiestas de l'assemblée du peuple en formation de comitiatus maximus, qui décide en dernier ressort; maiestas de l'empire de Rome auquel rien n'est opposable et que rien ne limite, étant maximum de par le monde; maiestas du prince qui porte dans sa titulature la double épithète jupitérienne d'optimus et de maximus, pour signi-

4. Ovide, Fastes, 5, v. 11 à 52, avec le commentaire de G. DumEzıL, op. cit. supra n. 1.

5. Clause de maiestas et supériorité d'une cité sur l'autre : Cić́ron, Pro Balbo, 36 et Proculus, Digeste, 49, 15, 7, 1 (J. L. Ferrary, "Les origines de la loi de majesté à Rome ", C.R. Académie des inscriptions et des belles-lettres, Paris, 1983, p. 562, voit au contraire dans la glose de Cicéron un indice que maiestas ne suffit pas à signifier une relation de supériorité); Charisıus, Syn. Cicenonis ordine litterarum composita, p. 427, Barwick. 
fier la plénitude d'un pouvoir arrivé à son degré d'excellence; maiestas de Dieu. Ainsi, la supériorité absolue du sujet de la majesté (magistrature, assemblée en position souveraine dans la cité, peuple romain maître du monde, empereur, Dieu) s'appuie sur un concept - maiestas - forgé pour signifier la majoration relative de son statut ${ }^{6}$.

Les "discrimina maiestatis" auxquels il a déjà été fait allusion montrent que, lorsqu'on la considère pour elle-même, la majesté est susceptible de degrés. On ne peut comprendre autrement le fait que TiteLive, par exemple, ait pu qualifier de supérieure la maiestas du peuple comparée à celle des consuls; ni le fait qu'entre magistrats de rang inégal l'inférieur le cède en majesté devant le supérieur, sans perdre la sienne pour autant; ni le fait que, sous le régime des lois tardo-républicaines, l'atteinte portée à la maiestas du peuple romain à travers les différentes magistratures de sa mouvance ait été qualifiée concurremment de diminution de leurs majestés respectives : celle du consul ou celle du tribun de la plèbe ${ }^{7}$. Il nous faut donc nous représenter la "grandeur", d'après ce régime, comme divisible, diffusée de haut en bas et inégalement répartie. À la persistance tardive d'une représentation de ce type, il convient d'attribuer encore la formulation trinitaire, officialisée par le Code Justinien, d'une égale majesté des personnes du Père, du Fils et de l'Esprit saint $^{8}$. De même qu'il faut à l'inverse supposer inégales les majestés divine et impériale lorsque s'affirme, dans la législation du Bas-Empire, l'idée que la seconde n'existe que par institution et délégation de la pre-

6. Sur la valeur superlative de maiestas, G. DumézlL, op. cit. supra, n. 1, p. 137 sq., qui tire cependant parti d'une majesté jupitérienne étrangère à la tradition plus ancienne. M. de Rome, puis du prince, voir infra. La m. de Dieu n'a pas d'incidence institutionnelle. Elle s'affirmera dès l'apologétique chrétienne des if et iIt siècles : Minutius Felix, 32, 1 ; TertulLIEN, Apol., 18, 3 (signes par lesquels Dieu fait connaître sa majesté dans le Jugement signa maiestatis suae iudicando - référence probable à Isaïe, 2, 17 et Ezéchiel, 43, 4, mais aussi à Exode, 40, 33 et à Deutéronome, 5, 24, passages où saint Jérôme traduira systématiquement le mot grec doxa, la "gloire ", par maiestas); Cyprien, Epist., 40, 1, 2; Соммоdianus, Carmen apologeticum, v. 102; Hilaire, De Trinitate, 5, 34, etc.

7. Maiestas maior: Trre-Live, 2, 7, 7 (cf. C.J., 1, 14, 12 : "quid enim maius [...] imperiali maiestate?"). Majestés relatives des magistrats entre eux : TrTE-LivE , 6, 6, 7 et 10, 24, 14. Atteinte à la m. des magistrats dans un régime de maiestas populi Romani : CrCERoN, Interrogatio in Vatinum, 22 (m. de l'imperium consulaire); Asconius, In Cornelianam, p. 61, Clark (m. du tribun de la plèbe); cf. en général Rhétorique à Herennius, 2, 12, 17; Cickron, De inventione, 2, 53; SÉNEQUE le Rhéteur, Controverse 9, 2 (exemple scolaire du proconsul Flamininus).

8. Par maiestas dans le dogme trinitaire: C.J., 1, 1, 1, sub pari maiestate; Filastruus (contemporain d'Augustin), Diversarum hereseon liber, 37, 2 (hérésie d'Hebion, qui refuse de reconnaître dans le Christ la même majesté qu'au père) ; 51,3 (égalité des trois personnes, " aequales in omni maiestate et potentia "). Voir aussi les nombreux passages de la Vulgate de Jérome, dont Luc, 9, 26, où m. traduit le grec doxa, la " gloire "; PrudenCe, Apotheosis, v. 255 sq. (nec enim minor aut patre dispar [...] vim maiestatis patriae habet filius) et $556 \mathrm{sq}$. (sur l'hérésie de ceux qui nient la divinité et la m. du Christ) et Psychomachia, v. 80. Bien avant Nicée, la christologie affirmait l'identité du Père et du Fils sous la figure de leur commune majesté (ainsi, CYprien, Epist., 59, 1, 2; Commodianus, Carmen apol., v. 467). 
mière ${ }^{9}$. Tout est donc bien affaire de hiérarchie. La " grandeur " déterminée au degré du comparatif (à un maior qui sert d'expression abstraite à la supériorité comme telle) est variable en ce double sens qu'elle se communique d'abord à des classes d'êtres placés à des hauteurs distinctes, jusqu'à celui placé au plus haut point d'éminence et doté par cela d'une absolue suprématie, et qu'elle se distribue ensuite par proportions inégales entre eux. Ainsi peut-on concevoir que les institutions élevées successivement au rang de maximus - c'est-à-dire, des origines républicaines au principat d'Auguste, successivement le magistrat, l'assemblée du peuple, la cité, le prince - aient été le point d'attache ultime et le principal foyer d'une maioritas fixée en elles comme en son lieu propre, sans cesser de garder sa valeur relative.

Tout en s'accordant à des situations d'absolue prééminence, la majesté latine est variable en sa mesure - en la mesure de sa supérieure grandeur -, et c'est là son caractère le plus singulier. Car, d'emblée, ce trait laisse voir ce qui la distingue de la souveraineté moderne : son aptitude à différer par le plus et par le moins. Au xvi siècle, la majesté est entièrement confondue avec la souveraineté. Les publicistes de la monarchie française, et Bodin en particulier, mais également les monarchomaques, ont cru voir dans le concept romain de maiestas l'équivalent de la souveraineté, en lui prêtant la fixité requise pour la construction dont celle-ci occupe le centre : toute république, et l'ultime sujet de la puissance en chacune d'elles, monarque ou peuple, possède absolument et indivisiblement la maiestas souveraine ${ }^{10}$. En contrepartie, comme on le voit claire-

9. La délégation de pouvoir consentie par la majesté divine à l'empereur (qui est un thème spécifique par rapport à l'idée générale d'élection divine) n'apparaît pas avant l'époque constantinienne (FImirCus Maternus, De errore profanarum religionum, 29, 4 ; LACTANCE, Institutions divines, 2, 19, 1; cf. la formule du serment militaire dans VÉGÉcE, 2, 5) ; ce thème, dépourvu d'ailleurs de toute portée juridique, n'entre pas avant le $v^{*}$ siècle dans les formulaires des lois (Novelles Théodosiennes, 17, 2, 6, a. 444; Novelles d'Anthemius, 3, pr., a. 468). La formule en sera transmise à l'Occident médiéval à travers la constitution Deo auctore de Justinien et la Novelle 112, 2.

10. La version latine de la République prend régulièrement maiestas dans le sens de souveraineté, de summa potestas (voir à la p. 78 du De republica, éd. de 1586 : "Maiestas est summa in cives ac subditos legibusque soluta potestas ", et nombreux autres passages : p. 153, droit de faire la loi comme primum caput maiestatis ; p. 234, jura maiestatis détenus soit par un seul, soit par quelques-uns, soit par tous; p. 300, maiestas au-dessus des lois, etc.); le texte français multiplie, face aux définitions de la souveraineté, les références à la maiestas des Romains : ainsi au chap. 10, «Des vrayes marques de Souveraineté », p. 218 de l'éd. de 1583. Mais Bodin n'est pas isolé : voir déjà Guillaume BuDE, Adnotationes in Pandectas, p. 96 de l'éd. 1551 de Bâle, à propos de Dig, 1, 9, 12, sur le transfert de maiestas opéré par la lex regia (alors que le texte d'Ulpien parle de ius et potestas); ALCiat, Opera, vol. IV, col. 816, éd. 1582 de Bâle, à propos de la lex " digna vox»; ou bien encore les Vindiciae contra Tyrannos, p. 82 de l'éd. 1579 d'Edimbourg : repraesentare populi maiestatem, cf. BouCHER, De justa Henrici Tertii abdicatione, I, 9 et III, 7, Paris, 1589. Il est intéressant de noter qu'Althusius lui-même définit la maiestas comme " potestas imperandi universalis " (Politica Methodioe Digesta. IX, 15, éd. Friedrich, Cambridge, U.S.A., 1932), tout en subordonnant 
ment chez Grotius, les majestés respectives des républiques juxtaposées les unes aux autres sont nécessairement égales, également déliées les unes des autres et absolues, aucune n'étant placée dans une hiérarchie de grandeurs relatives à l'intérieur d'un même ordre de subordination " ${ }^{\text {. }}$ La souveraineté moderne s'apparente par là au centre abstrait d'un espace clos, fermé aux autres espaces clos qui l'entourent : centre unique auquel sont rapportés en dernier lieu la totalité des actes de la puissance publique, mais centre mis à parité avec d'autres, égaux en autonomie. Par cette opération axiomatique, les pouvoirs accrédités à l'intérieur de l'entité politique se réduisent à l'unicité propre à cette entité, en même temps que cette entité se reconnaît comme finie dans un monde où se côtoient les unités. Or une telle imputation traduit l'essence si l'on ose dire inquantifiable de l'État. À la différence de la majesté, la souveraineté de l'État est étrangère à l'idée quantitative, parce qu'elle n'est autre que la formule de son unité et de son autonomie. Il n'y a pas plus de sens à la jauger qu'il n'y en aurait à arpenter l'individualité d'un individu; et pas plus de cohérence à distinguer plusieurs degrés en elle qu'il n'y en aurait à établir une échelle de l'identité à l'intérieur de l'identité d'un sujet. L'instance de la souveraineté se distingue du point culminant de la majesté (du degré "maximal" de la maiestas) en ce qu'il est en même temps son siège unique. Non plus un foyer d'où elle se répandrait par degrés inégaux, comme la majesté romaine toujours plus ou moins grande, toujours plus ou moins haute, majesté déployée par paliers, mais le centre immobile, indivisible et inextensible où elle se réduit.

Mais la souveraineté est invariable en un autre sens qui l'oppose encore à la majesté. Car n'entre pas dans sa notion proprement dite l'ampleur du substrat placé sous elle, territoire ou population unifiés dans sa mouvance. En toute rigueur, il est indifférent au concept même de souveraineté que son substrat, territoire ou population, augmente ou diminue (de même que, en théorie du droit, les changements du corps et les variations du patrimoine n'affectent pas l'irréductible unicité du sujet). $\mathrm{La}$ souveraineté est ou n'est pas : la présupposition même de ce qui l'affecterait quantitativement est absurde et contraire à la logique de la construction étatique, comme l'a si bien vu Kelsen ${ }^{12}$. La maiestas, au contraire, est portée à s'étendre en même temps que s'accroît cela même dont elle est la grandeur : le pouvoir, Rome, l'Empire romain. Elle fait corps avec la puissance réelle et matérielle du pouvoir, de la cité, de l'empire qui la

la puissance aux "leges Maiestatis " (XXIV, 48), ce que je crois être une allusion à la clause " ex maiestate [...] rerum" de la lex de imperio (sur laquelle infra, p. 343).

11. Gronus, De iure belli ac pacis, Livre I, chap. 3, 21 (interprétation restrictive de la clause de majesté des traités inégaux du droit romain).

12. H. Kelsen, Théorie pure du droit, Paris, 1962, p. 438. 
possèdent. À cette conception correspond l'expression formulaire augere maiestatem, « augmenter la majesté ». Lui correspond aussi l'idée qu'une diminution de son amplitude est constitutive du crime perpétré contre elle (minuere maiestatem). En sorte que la supériorité dont il s'agit varie non seulement en degré, selon le rang qu'occupe l'être qu'elle situe, mais aussi en étendue, suivant le mouvement d'expansion de cet être : peuple, empire, monarque. Sa variabilité montre une fois de plus que, même lorsqu'elle s'entend au sens superlatif parce qu'elle appartient à une instance supérieure absolument, elle ne cesse pas d'être relative, à cause de ses mouvements. Souvent, on aura l'occasion d'y revenir, les Romains définissent la maiestas, en dehors de toute relation, comme la grandeur même, magnitudo. Mais ce n'est pas une valeur constante qu'ils entendent immobiliser par ce mot. Car cette grandeur peut être entamée ou au contraire gagner encore du terrain, poursuivre son amplification, comme le dit Tite-Live à propos du destin historique de Rome, en sorte que ce qui paraît fixé dans l'absolu reste un maior appelé à se surpasser soi-mème indéfiniment ${ }^{13}$.

D'une manière plus précise, la grandeur de la majesté était conçue sur un plan institutionnel. Sous cette appellation, l'échelle des ordres et des rangs offrait une construction qui n'excédait pas les limites de ce que les Romains avaient façonné pour ordonner leur existence civile. Il ne pouvait être question de majesté au-delà de la constitution politique - et notamment pas dans la nature, malgré l'étagement sous lequel les Anciens se figuraient la structure du monde ${ }^{14}$. À Rome, les choses institutionnelles avaient très tôt été conçues sur un plan de réalité autonome, et les concepts qui les régissaient restaient soumis à leur usage propre. L'arrangement des classes dans l'ordre politique obéissait à un régime distinct de celui qui convenait à la disposition des êtres dans le cosmos. Nulle transcendance ne redoublait en hauteur la culmination de ce qui

13. Sur le rapport avec magnitudo ou amplitudo, voir FEsTus, p. 126 L. (maiestas a magnitudine dicta) et certains textes rhétoriques républicains cités par J. L. FERRARY, op. cit. supra n. 5, p. 562. Sous l'Empire, ces mots s'équivalent (Tacte, Annales, 2, 79 ; Pline, Panégyrique, 42, pr. ; АмMIEN, 14, 5, 4 ; 30, 14, 5 ; MACrobe, Sat., 1, 12, 17). Majoration indéfinie de la m. : Trte-Ljve, Praef., 11 ; cf. Dioclenen, in Collatio Mosaicarum et Romanorum legum, 6, $4,6$.

14. Chez Pline l'Ancien, la «majesté de la nature " rehausse des matières précieuses qui servent aux ornements du pouvoir, comme les gemmes (Histoire naturelle, 37, 1); ou bien elle exprime l'infinie diversité des espèces, dans une acception numérique de la grandeur (7, $7 ; 18,5)$ : mais on ne la voit jamais associée à la hauteur d'une instance supra-humaine, et son absence dans l'évocation des sphères célestes est en soi significative. Je ne connais en tout et pour tout qu'un passage de SÉnk̇uE où maiestas serve à définir la position éminente des astres (De beneficiis, 4, 24, 1). Chez LuCRECE, la maiestas rerum n'est pas comme on le traduit trop souvent la " majesté de la nature ", mais celle des découvertes d'Epicure, supérieures à celles que l'on attribue aux divinités : autrement dit, la connaissance et la sagesse (Nat. rer., 5, 2 sq.). 
pour le droit était situé au plus haut. Nulle transcendance et, faut-il ajouter, pour éviter d'emblée de confondre le terrain juridique où fut élaboré ce concept avec ses prolongements émotionnels qui n'en sont que l'accessoire, nul éclat numineux, nulle force mystique, nul rayonnement charismatique ne sont au principe de la majesté ${ }^{15}$. Il est significatif que la supériorité dont les dieux jouissaient sur les hommes ne fut, pendant très longtemps, pas définie ainsi. Aucune maiestas divine ne nous est signalée dans les sources les plus anciennes ni dans celles qui nous transmettent une tradition d'origine sacerdotale, juridique ou annalistique. Malgré l'opinion contraire la plus répandue, il n'y a rien d'orthodoxe ni d'archaïque dans une telle caractérisation de la place qu'occupe la divinité. On ne la voit pas énoncée avant les ouvrages didactiques de Cicéron ni surtout avant les poèmes d'Ovide, à l'époque d'Auguste. On n'échappe pas à l'impression d'un emploi secondaire et métaphorique ${ }^{16}$.

15. On a trop souvent insisté sur l'éclat et le rayonnement mystiques de la majesté, au détriment de la construction juridique qui la sous-tend, sous le prétexte qu'elle apparaît quelquefois comme vénérable, stupéfiante, terrifiante, etc.; c'est prendre l'effet pour la cause et l'accessoire pour le principal. Ainsi, E. Pollack, op. cit. supra n. 1, p. 25 sq.; U. KNOCHE, " Die geistige Vorbereitung der Augusteischen Epoche ", dans Das neue Bild der Antike, H. Berve, éd., 2, Munich, 1942, p. 214 ; F. TAeger, Charisma, 2, Stuttgart, 1960, p. 266 sq. ; H. Wagenvoort, Roman Dynamism. Studies in Ancient Roman Thought, Language and Custom, Leiden, 1947, p. 123 sq., rattache aux représentations primitivistes du mana l'idée romaine de maiestas (voir la critique décisive de G. Dumezı, op. cit. supra $n$. 1). Pour une interprétation de maiestas sur le registre exclusif du numineux, voir $H$. DREXLER, « Maiestas ", dans Aevum, 1956, p. 195-212, repris dans Politische Grundbegriffe der Roemer, Darmstadt, 1988, p. 31-48. Signalons pour mémoire l'idée singulière qu'a eue M. A. Levi de fonder $\mathrm{m}$. sur la "croissance agraire " et sur la "force de germination », à cause d'une parenté étymologique avec Maia et Mater Magna, relevée par Cornelius LABeo : « Maiestas et crimen maiestatis ", La Parola del passato, 1969, p. 81-96.

16. La priorité de la maiestas deorum dans le temps est postulée notamment par G. Dumezil, op. cit. supra n. 1, p. 129, par J. HellegouAR'CH, op. cit. supra n. 2, p. 315 et par R. A. BAUMAN, The Crimen maiestatis in the Roman Republic and the Augustan principate, Johannesbourg, 1967, p. 4 sq. Pour l'époque précicéronienne, le fragment $n^{\circ} 8$ Ribbeck de l'Egisthe de Livius Andronicus a été abusivement sollicité par H. WAGENVOORT, op. cit. supra n. 15, p. 121 et par G. Dumtzil, loc. cit. : le personnage qui se qualifie par les mots "maiestas mea " est probablement un roi, comme l'a bien vu H. G. GUNDEL (art. cit. supra n. 3, p. 313). En fait, elle n'est pas attestée avant les traités de Cicéron (De natura deorum, 2, 77; Académiques, 2, 120 ; cf. De divinatione, 1, 182 et 2,101-102, où l'on voit qu'il n'est pas contraire à la majesté des dieux de communiquer l'avenir aux hommes). À l'époque augustéenne, elle est une spécialité d'Ovide (Pontiques, 4, 8, 55; Métamorphoses, 2, 847 et 4, 540 ; Fastes, 2, 847 et surtout 5, 11 sq. ; cf. infra, p. 381 sq.). La métaphore juridique d'une diminution de leur majesté n'est pas employée avant SÉNĖQUE, Naturalis historia, 1, praef., 3 (cf. ARnobe, Nat., 4, 27 ; LaCtanCE, Institutions divines, 2, 4, 36). L'idée semble s'être cependant répandue par la suite au-delà de l'élaboration littéraire. Ainsi PAuL, Digeste, 4, 8, 32, 4 ; un prêtre ne peut être astreint à rendre un arbitrage, "à cause de la majesté des dieux, pour le service desquels les prêtres doivent rester libres ". Quelques exemples épigraphiques des If et III siècles sont apportés au dossier par P. VEYNE, qui note la tendance, au cours du paganisme de ce temps, à s'adresser au dieu comme à l'empereur (" Une évolution du paganisme gréco-romain : injustice ou piété des dieux, leurs ordres et oracles », Latomus, Bruxelles, 1986, repris dans La Société romaine, Paris, 1991, p. 281-310, not. p. 307 sq.). 
Cette spécialité politique de la majesté est d'autant plus frappante que, par ailleurs, la magistrature entretenait de nombreuses affinités de principe avec Juppiter. C'est moins à la fonction royale de Juppiter et à la ressemblance jupitérienne du roi et du magistrat, qu'il est fait allusion ici, que plus précisément au fait que le magistrat supérieur et le dieu étaient l'un comme l'autre qualifiés de maximus. Le dieu, parce qu'il occupait un rang de suprématie par rapport à l'ensemble hiérarchisé des êtres divins et humains, au plus haut d'une pyramide dont il occupait à lui seul le sommet ; mais aussi parce que, comme celui du roi, son statut était caractérisé par la plénitude : son titre officiel de Juppiter Optimus Maximus exprimait tout à la fois l'excellence et l'entièreté de son statut (de même que, dans la langue du droit, on appelait optimus maximus un fond qui n'était grevé d'aucune servitude) ${ }^{17}$. Le magistrat, lorsque sa place était au plus haut dans la hiérarchie et qu'il jouissait d'un pouvoir intègre, au sens où l'on pouvait parler d'imperium maximum, d'un pouvoir à plein régime $^{18}$. Au plan religieux comme au plan politique (et peut-on ajouter, au plan sacerdotal, avec le pontifex maximus), le degré superlatif de " grand " connaissait ainsi un double emploi; il pouvait signifier aussi bien l'éminence que l'intensité d'un pouvoir; son élévation hiérarchique et son entièreté; et, le plus souvent, l'un et l'autre à la fois.

Le même parallélisme s'observe encore avec le degré du comparatif. Maior s'appliquait aux divinités supérieures du panthéon comme aux magistratures du premier ordre. De la même manière que la théologie

17. La signification juridique précise d'optimus maximus est "libre de servitudes " (cf. Digeste, $21,1,61 ; 21,2,48 ; 50,16,169)$ : mode de représentation négatif, on le voit, du plein droit. Sur J.O.M., voir l'analyse de G. RADKE, "Iuppiter Optimus Maximus : dieu libre de toute servitude ", RHD, 1986, p. 1-17 et Zur Entwicklung der Gottesvorstellung und der Gottesverehrung in Rom, Darmstadt, 1987, p. 240 sq. Il faut ajouter les remarques de J. MARTIN sur optimum ius : "Die Dictatur optima lege", ZSS.RA, 1989, p. 557-572. N.B. On orthographie ici « Juppiter » en suivant la norme phonétique.

18. Sur le sens juridique de maximus, qui désigne à la fois la position la plus élevée dans la hiérarchie et, ce qui ne revient pas au même, l'intégrité d'un pouvoir souverain, il faut se reporter à l'étude fondamentale d'A. MAGDELAIN, "Praetor maximus et comitiatus maximus", IURA, 20, 1969, p. 257-286 = Ius, Imperium, Auctoritas. Etudes de droit romain, École fr. de Rome, 1990, p. 313-339. L'imperium maximum est attesté dans un responsum de 217 chez Trte-Live, 22, 10, 10, par VARron, De lingua latina, 7, 85 et par Festus, p. $152 \mathrm{~L}$. Sous le Principat, les monarques intégreront la formule optimus maximus à leur titulature, d'abord sous une forme disjointe : ainsi Claude, qui est le premier à se faire appeler optimus princeps (CIL, 10, 1401 ; Puine, Ep., 8, 6, 10) et princeps maximus (SÉnèque, Dial., 11, 6, 5), ou Trajan, qui ne porte lui aussi qu'optimus dans sa titulature (ILS, 295 à 298 et 304); puis en la reprenant intégralement : Caligula (Suettone, Cal., 22), Néron (Ś́nèque, Clem., 1, 19, 9), Antonin le Pieux (ILS, 341, 345), Septime Sévère (ILS, 437, 439, 440), etc. ; cf. principes optimi maximique dans Digeste, 27, 1, 30, pr.; 34, 9, 16, 1;48, 19,39. Ce titre ne les fait pas seulement ressembler à Juppiter (ainsi J. R. FeArs, Princeps a Diis electus, The Divine Election of the Emperor as a Political Concept at Rome, Rome, 1977, p. 138), mais signale surtout la complétude de leur pouvoir, sa caractérisation par l'absence d'entraves, comme le montre a contrario l'interprétation modératrice de SéNĖQue, Clem., loc. cit. supra. 
divisait les dieux entre ceux relevant des flamines maiores et minores ${ }^{19}$, le droit public organisait autour de l'opposition maior/minor la répartition des fonctions, des pouvoirs et des auspices. Or maior oscillait lui aussi entre la précellence du rang et l'intégrité de la compétence, à tel point que son usage s'avère dans certains cas exactement le même que celui de maximus. On le voit dans les "auspices majeurs" qui sont une autre expression des " auspices maximes "; dans le consul maior, qui succède au plus ancien magistrat qualifié de maximus à l'époque archaïque; ou bien encore dans l'imperium maius à la fin de la République, qui fait probablement écho à l'imperium maximum connu au III siècle avant notre ère $^{20}$ - désignations auxquelles fait pendant, au plan divin, le Juppiter auquel rien ne peut être dit maius et que l'on identifie pour cela à Maius, éponyme de mai ${ }^{21}$.

Les mêmes oppositions classificatoires, soit avec maximus soit avec maior comme premier terme, servaient à structurer hiérarchiquement les institutions du droit public et le monde des dieux. Dans un cadre civique, elles ordonnaient, selon les principes combinés du rang et de la puissance, les agents et les pouvoirs qui gouvernaient les rapports entre hommes ou entre hommes et dieux. Aux dieux eux-mêmes s'appliquait ce mode de division, si bien que la cité et le ciel pouvaient paraitre identiquement organisés. Ces analogies rendent d'autant plus frappant le fait que le concept de majesté n'ait pas d'usage en dehors du droit politique. Â l'inverse de ce que l'on a souvent écrit, son ressort jupitérien s'avère une image tardive et d'ailleurs fort peu exploitée. Cette image s'enracine dans un terrain depuis longtemps déjà constitué en droit ${ }^{22}$. C'est une grave erreur d'attribuer une origine religieuse à ce qui n'est que l'expression abstraite du statut de supériorité pensé à l'intérieur d'un régime institutionnel; et c'en est une plus regrettable encore que de l'appliquer aux

19. Sur la hiérarchie divine rapportée à celle du flaminat, G. Dumfzil, La Religion romaine archaiqque, Paris, 1966, p. 114 sq.

20. Le praetor maximus et le maximus magistratus (ILLRP, 319) des premiers temps de la République sont devenus par la suite le maior consul (Festus, p. $161 \mathrm{~L}$ ), de même que les auspicia maxima (Messala chez Aulu-Gelle, Nuits attiques, 13,15) se sont transformés en auspicia maiora (FEstus, p. $148 \mathrm{~L}$ ), probablement au cours du III siècle : A. MAGDelain, op. cit. supra n. 18, p. 324 sq. Chez TrTE-Lrve, 7, 3, 8, l'imperium maius du dictateur chargé d'apaiser rituellement les épidémies succède au magistrat maximus dont c'était l'office. Voir W. O'NeAL, " Maius Imperium ", RSCL, 1979, p. 390-394.

21. Juppiter et Maius : MACROBE, Satumales, 1, 12, 17.

22. Au livre 5 des Fastes, Ovide fait de Maiestas la gardienne du sceptre de Juppiter magnus, comme celle des faisceaux des rois et des magistrats : voir infra, p. $381 \mathrm{sq}$. Cette attribution est une grande première qui n'a aucun écho ni chez les poètes (et notamment pas chez Virgile, en dépit de la maiestas des Latins dont Juppiter Latiaris est tutélaire : supériorité qui ne s'exprime qu'au plan humain : En., 12,820 sq.), ni sur les monnaies et les inscriptions. Il faut attendre MACROBE, au Iv siècle, pour voir à nouveau proclamer ouvertement la majesté comme un attribut du dieu : Saturnales, 1, 12,17; deus Maius (éponyme de mai), " a magnitudine scilicet et maiestate dictus". 
deux ordres de subordination politique et sacral indifféremment. Encore même doit-on préciser que le statut de majesté, à l'intérieur des institutions politiques, prend son sens à l'égard des agents de la puissance civile, à l'exclusion du sacerdoce. En ce qu'il attache une valeur juridique aux relations inégales entre les classes où se répartissent les êtres, ce statut ne s'étend pas à la sphère sacerdotale : il n'est pas plus un attribut du pontifex maximus que d'aucune autre prêtrise. En suivant le cours de l'histoire, depuis les origines royales jusqu'à l'empire en passant par la république, les textes latins reconnaissent la majesté successivement au roi, au magistrat, au consul, au dictateur, au censeur, au triomphateur, au préteur, au sénateur patricien, au tribun de la plèbe, au peuple, au sénat, au prince; à Rome même, à la Cité, à la République, à la Ville, à l'Empire romain; le père de famille lui-même est rehaussé d'une maiestas patria. Mais les agents spécialisés du commerce divin, les techniciens du sacré en sont régulièrement dépourvus, autant que l'étaient traditionnellement les dieux eux-mêmes. Le silence des textes à leur sujet doit être pris pour une donnée significative ${ }^{23}$.

Si l'on veut partir d'une base claire, il faut commencer par prendre acte de l'essentiel : le point culminant de la majesté appartient au monde sublunaire des institutions humaines. Il caractérise d'abord un statut de supériorité d'où le divin, si élevé soit son rang au-dessus des hommes, et d'où les spécialistes du divin sont absents. Ce statut acquerra au cours des temps la force d'un véritable état juridique de la majesté, entouré d'interdits et hérissé de procédures : le crimen maiestatis restera dans la très longue durée de la structure politique occidentale - jusqu'à la fin de l'Empire romain puis de nouveau, après la rupture du haut Moyen Âge, à partir de la fin du xil siècle - le rempart d'une Grandeur constituée en droit par son inviolabilité même. Autour du crime s'élaborera, pendant les longs siècles de l'Empire romain, la défense de ce qu'il faut bien appeler un état juridique de la Majesté (une causa maiestatis, une conditio maiestatis, pour reprendre une formule qui place ce concept sous la détermination d'une condition permanente, comme dans status reipubli$c a e^{24}$ ). Un état de la référence à la grandeur qui ne peut être encore qualifié d'État, pour toutes sortes de raisons de fond dont la moindre n'est pas l'extensibilité du contenu de cette référence et le régime purement défensif qui s'organise autour d'elle. Un état de préservation de la supériorité

23. Le seul texte que l'on pourrait citer est Festus, p. 272 bL : « parmi les 15 Flamines, le flamen Dialis est le premier en dignité (maxima dignatio) et, comme ils observaient entre eux des distinctions de hiérarchie bien précises (certa discrimina maiestatis), le Pomonalis était le dernier. » Mais maiestas ne distingue pas ici une fonction particulière, dont elle fixerait le rang propre : elle désigne toute hiérarchie en général et en tant que telle. PauL, Digeste, 4, 8, 32,4 , loc. cit. supra $\mathrm{n}$. 16, ne parle pas de la $\mathrm{m}$. des prêtres, mais des dieux.

24. Voir infra n. 52. 
qui se conçoit aux antipodes de l'action positive et offensive de la souveraineté moderne, laquelle ne se base pas d'abord sur les interdits qui la sauvegardent, mais sur sa propre puissance d'effectuation. Un état, enfin, auquel la construction politique médiévale (pontificale et royale) empruntera grand nombre de ses structures et de ses techniques, à travers le corpus d'un droit romain réinterprété et rénové - en sorte que la structure institutionnelle de la majesté romaine traverse l'histoire politique d'Occident jusqu'au début de l'époque moderne, mais avec cette originalité remarquable, par rapport à sa forme romaine antique, que la Majesté y aura d'abord son siège en Dieu. Arrêtons-nous un instant sur cette différence, avant de reprendre le cours de notre analyse.

J. Chiffoleau a montré quel mélange explosif, dans les pratiques institutionnelles, a provoqué cette savante adaptation, facilitée par le travail interprétatif des canonistes et des romanistes, des procédures de la lèsemajesté romaine à la théologie de la Majesté divine. L'hérésie est qualifiée alors d'atteinte à la Majesté de Dieu. Elle est poursuivie selon les formes d'enquête mises au point à Rome pour la maiestas impériale, tandis que la poursuite des atteintes à la Majesté du roi, par un parcours en sens inverse, réintègre une acclimatation politique de l'hérésie. Un double transfert s'opère ainsi de l'État à Dieu et de Dieu à l'État. Et non plus seulement, comme on le savait depuis longtemps déjà, sur le terrain de l'idéologie politique, des représentations et des idées, mais sur celui, plus concret et plus vital, de la juridiction inquisitoriale ${ }^{25}$. Or un échange aussi intense entre l'ici-bas et l'au-delà à l'intérieur même des pratiques institutionnelles est proprement impensable à Rome, malgré tous les dieux qui peuplaient son univers politique. D'abord, parce que les dieux avaient leur place non moins que les hommes dans ce monde-ci, où ils occupaient certaines sphères; mais leur existence, quoique le plus souvent invisible et intangible, était relativement proche, et la communication avec eux multiple, d'inégale intensité et diffuse, malgré certains rythmes auxquels elle devait obéir. Cet échange n'était pas monopolisé par un centre institutionnel puissant, médiateur exclusif par lequel aurait pu être rendu présent un Dieu infini, unique et inaccessible autre-

25. J. Chiffoleau, dans l'ouvrage qu'il prépare avec moi sur l'histoire de la majesté en Occident et dans de nombreux travaux préparatoires, dont : «Sur la pratique et la conjoncture de l'aveu judiciaire en France du xuI' au $x^{e}$ siècle ", in L'Aveu. Antiquité et Moyen Age, Ec. Fr. Rome, 1986, p. 341-380 et « Dire l'indicible. Remarques sur la catégorie du nefandum du XI" au xv siècle ", Annales, ESC, 2, 1990, p. 289-324, J'ajoute que, du point de vue de l'antiquisant et du juriste que je suis, les travaux de certains médiévistes sur les persécutions et sur l'inquisition médiévales (je pense à ceux si remarquables de Norman Cohn, de Carlo Ginzburg ou de Robert L. Moore) paraissent négliger exagérément l'autonomie de la construction politico-institutionnelle prise dans sa très longue duré, au profit d'une histoire sociale des représentations. 
ment que par une organisation infaillible du miracle de sa présence ${ }^{26}$. Les articies de foi sur la nature de la divinité n'avaient pas à être unifiés en dogmes dont la vérité eût été à la mesure de sa toute-puissance et l'observation nécessaire à l'unité de ses fidèles. Une telle fusion du haut et du bas dans le creuset de l'institution politique était inimaginable, enfin, parce que la Majesté institutionnelle, précisément, n'était pas le reflet d'une transcendance qui en aurait été le siège véritable. Elle était autonome et suffisante. Nulle majesté divine, à Rome, ne relativise celle de la puissance publique, pas même au temps du christianisme officiel d'empire à partir du Iv siècle, alors même que la Majesté de Dieu est proclamée ouvertement comme la source de tout pouvoir impérial, selon la formule de l'imperium a caelesti maiestate traditum, recueillie par Justinien ${ }^{27}$. Car cette référence céleste ne reçoit pas encore, comme cela devait advenir au Moyen Âge, une forme de reconnaissance juridique, que seule aurait pu lui conférer la sanction d'un crimen : le crime de lèsemajesté divine, traduction politico-juridique de l'hérésie. Elle n'était encore que théorique. La maiestas romaine tardo-antique, comme celle des époques plus anciennes, continue d'exclure dans sa pratique sinon dans son principe tout lieu qui ne soit pas immanent au monde de la politique et du droit.

Sous l'Empire, cependant, la loi d'investiture des princes (lex de imperio, qualifiée plus tard de lex regia) comportait une clause autorisant l'empereur à ordonner et à faire tout ce qui lui semblait conforme «à l'utilité de la République et à la Majesté des choses divines et humaines, publiques et privées ". Ce pouvoir - que les juristes des II $^{e}$ et III $^{e}$ siècles devaient interpréter comme un pouvoir de légiférer - nous est connu par la charte épigraphique du principat de Vespasien. Mais la clause qui l'énonce rappelle qu'il avait été conféré dans les mêmes termes « au divin

26. On pense ici à la doctrine de la légalité des sacrements, efficaces de par la seule ordination, formulée par Augustin et recueillie dans le Décret de Gratien, C. 1 q. 1 c. 29 sq.

27. Constitution Deo auctore, $\$ 1$. Autres références supra $n$. 9. Sur l'idée romaine d'élection divine, de mandat reçu de la divinité, et sur les transformations de cette idée à l'époque du christianisme, la bibliographie est innombrable : l'essentiel est dit par W. E. ENssLIN, "Gottkaiser und Kaiser von Gottes Gnaden », SBAW, 1943, repris dans Das byzantinische Herrschersbild, éd. H. HUNGER, Darmstadt, 1975, p. 54-85 et par J. R. FeARS, op. cit. supra n. 18 ; également S. CALDERone, "Teologia politica, successione dinastica e consecratio in età costantiniana ", dans Le Culte des souverains dans l'Empire romain, Entretiens de la fondation Hardt, 19, 1972, p. 215-261. La plupart des travaux s'en tiennent cependant à une analyse des idées, des représentations, de la propagande et des croyances : il manque une réflexion conduite sur le terrain de la pensée institutionnelle (sur les incidences religieuses dans le vocabulaire des constitutions impériales à partir du rv siècle, voir cependant l'étude de R. M. Honig, Humanitas und Rhetorik in spätrömischen Kaisersgesetzen, Göttingen, 1960; également, l'étude méthodologiquement importante de J.-M. Carré, " La munificence du prince. Les modes tardifs de désignation des actes impériaux et leurs antécédents ", dans Hommage à A. Chastagnol, à paraître. 
Auguste, à Tibère et à Claude " - c'est-à-dire, depuis le fondateur de la monarchie jusqu'à la date de 70 , à tous les princes dont on pouvait invoquer le précédent parce que leur mémoire n'avait pas été condamnée. Il est donc un article constitutionnel permanent. D'après la formule, le droit que détient l'empereur de " décréter et d'exécuter " (agere facere ius potestasque) s'ordonne à l'utilité publique d'un côté (ex usu reipublicae) et à une «majesté " peu définie, embrassant la totalité de la sphère divine et humaine, de l'autre. Mais comment comprendre l'idée d'une conformité de la loi à la grandeur des "choses " propres à ces deux sphères? La formulation d'une maiestas divinarum humanarum rerum, d'ailleurs unique dans le droit public du principat et réservée à sa charte constitutive, laisse-t-elle apparaître une réduplication de la normativité en hauteur? Et quelie peut être la portée d'un pareil déplacement ${ }^{28}$ ?

À en juger par celle que recouvre habituellement en grec la révérence envers les hiera kai hosia, qui ont leur équivalent dans les res divinae humanae, on pourrait imaginer que la loi d'investiture, dès Auguste, réfère la validité des actes d'autorité à une légalité transcendante. Cicéron avait divulgué cette formule dans nombre d'ouvrages didactiques où la " connaissance des choses divines et humaines " était proposée comme fin de toute sagesse. La rhétorique utilisait au besoin ce cliché pour disposer les lieux de l'argumentation juridique, et les prudents n'hésitaient pas à l'acclimater à leur langage, lorsqu'ils ouvraient l'exposition de la science du droit par la considération de l'indépassable hauteur de la sphère où se mouvait leur art. Il nous est resté au Digeste un texte célèbre des Règles d'Ulpien, jurisconsulte officiel au temps des Sévères, reproduit dans les Institutes de Justinien et glosé par des générations d'interprètes au Moyen Âge : la jurisprudence y est définie comme une « divinarum atque humanarum rerum notitia ${ }^{29}$. Cependant, le sens du sublime juri-

28. CIL, 6, 167, 1.17 sq. T. Mommsen, Das röm. Staatsrecht, II, $3^{c}$ éd., Leipzig, 1888, p. 909 sq., simplifie le problème en traduisant « le droit de faire, dans les affaires divines et humaines, publiques et privées, tout ce qui lui paraîtra conforme au bien (usus) et à la grandeur (maiestas) de l'État ", ce qui fait de respublica le déterminant commun d'usus et de maiestas, alors que le texte distingue 1 ' « usus reipublicae » d'un côté et la "majesté des choses divines et humaines publiques et privées », de l'autre. Certains, dans le même esprit, sont allés jusqu'à réécrire la formule en rajoutant un " que » à maiestas, pour isoler le groupe de mots " usus reipublicae maiestasque », alors que le texte de l'inscription les disjoint (ainsi H. KRELLER, dans ZSS, 1920, p. 265 et M. SARGENT, "Considerazioni sul potere normativo imperiale ", dans Scritti A. Guarino, Naples, 1984, 6, p. 2633). A. PABst interprète avec raison, contre Mommsen, " respecter la majesté de ces choses " (« Annăherungen an die lex de imperio Vespasiani ", dans Festschrift Robert Werner, Constance, 1989, p. 128).

29. Ulpien, Digeste, 1, 1, 10,2; Inst., 1, 1, 1. Ce sont les termes mêmes par lesquels Ciceron définit la sapientia (Tusculanes, 4,$57 ; 5,7$; De officiis, 1,$153 ; 2,5$, cf. Lactance, Institutions divines, 3, 13, 10; De finibus, 2, 37; De oratore, 1, 212 : " philosopher, c'est s'appliquer à connaître le sens, la nature et les causes de toutes les choses divines et humaines ", définition reprise par les philosophes chrétiens (Jéróme, Commentaire sur Isaïe, 2, 21; Com. in ep. ad Eph., 1, 9; Augustin, Contra Academicos, 1, 6, 16 sq.) et transmise à travers les Etymolo- 
dique se perd si l'on oublie que, pour les dogmaticiens romains, " choses divines et humaines " n'avaient d'autre mode d'existence que celui d'institutions produites artificiellement. De ce point de vue comme de tant d'autres, les lieux communs de la métaphysique classique avaient été réemployés pour l'édification d'une légalité qui, à Rome, occupait le champ reconnu en Grèce à la nature.

Prenons l'exemple de Varron, dont les Antiquités, rédigées autour des années $\mathbf{5 0}$ avant notre ère, se composent de vingt-cinq livres de res huma$n a e$ et de seize livres de res divinae. Dans cette encyclopédie, trésor d'érudition auquel puiseront les antiquaires jusqu'à la fin du monde romain antique, les "choses " avaient purement et simplement statut d'institutions. Les hommes y étaient envisagés avant les dieux parce que "les cités d'abord avaient été fondées "; puis venait ce qui avait été institué par elles, c'est-à-dire le culte des dieux. Car, "de même que le peintre est antérieur au tableau et l'ouvrier à l'édifice, de même les cités sont antérieures aux choses constituées par elles ${ }^{30}$. Le plan de ce vaste système s'ordonnait à la logique d'une action pensée dans le temps et dans l'espace de la cité. La partie réservée aux institutions divines commençait par les agents publics de l'action sacrée, c'est-à-dire par les divers sacerdoces, puis s'enchaînait sur les temps prescrits (le calendrier), les lieux consacrés (temples et sanctuaires), les choses objet d'une consécration (sacrifices publics et privés), enfin les destinataires des sacrifices (les dieux, à propos desquels était développée toute une théologie civile). Cinq siècles plus tard, Augustin s'indignera que les "choses divines", qui pour un chrétien ne pouvaient avoir d'autre sens que celui de nature créée par Dieu, eussent été, de l'aveu même de Varron, mises au rang des productions humaines et jugées de la même essence que la peinture ou l'architecture, « ut hominibus institutae ${ }^{31}$.

La catégorie des « choses divines et humaines » dont était proclamée la maiestas regroupait finalement l'ensemble du droit positif compris dans ses divisions canoniques. La formule était librement adaptée à toutes sortes de définitions. À celle de la jurisprudence dans son ensemble,

gies d'IsIDORE, 2, 24, 2 : « philosophia est rerum humanarum divinarumque cognitio. » L'utilisation de cette formule pour définir la jurisprudence en fait donc une rivale de la philosophie (cf. UlPIEN, Digeste, 1, 1, 1, 1 : veram nisi fallor philosophiam, non simulatam affectantes).

30. Varron, ap. Augusmin, Civitas Dei, Livre 6, chap. 4.

31. Augustin, $C i v$. Dei, 6, 5, 3; également 4, chap. 1, sur l'inintelligibilité, pour un chrétien, de ce mode de rapport entre le divin et l'humain. Les " choses humaines " elles-mêmes ne concernent que la cité romaine, à l'exclusion du reste du monde. Sur le plan de Varron, voir M. SchaNTZ, Geschichte der römischen Literatur, $3^{e}$ éd., I, 2, Munich, 1909, p. 435; H. Dahlmann, RE Suppl., VI, c. 1234 sq. ; A. G. Conderni, préface aux fragments des deux premiers livres des Antiquitates Rerum Divinarum, Bologne, 1967, p. VII sq. ; B. Cardauns, dans son édition de Wiesbaden, 1976. 
comme on le voit chez Ulpien, mais déjà aussi chez Cicéron, lorsqu'il définit par cette formule le domaine de consultation des pontifes ou les lieux de l'argumentation dans les causes légales : l'art juridique recouvrait alors le droit sacré d'un côté et le ius civile de l'autre (cette dernière branche excluant la science des rites et la technique des rapports d'obligations entre hommes et dieux $)^{32}$. Ou bien elle était employée pour définir tel domaine normatif ou telle institution en particulier : les biens étaient ainsi divisés d'après leur appartenance soit aux dieux ou aux morts, res divini iuris, d'un côté, soit aux hommes, res humani iuris, de l'autre; le mariage opérait une «communication du droit divin et humain ", à cause de la conjonction qui s'y produisait entre rites religieux et actes juridiques, telle la constitution de $\operatorname{dot}^{33}$. Droit divin d'une part, droit humain, connu sous ses deux genres public et privé, d'autre part : telle était en doctrine la summa divisio de l'ensemble institutionnel. À la supérieure majesté d'une totalité institutionnelle ainsi structurée - et non pas à celle d'une nature antérieure au droit - la lex de imperio rapportait, depuis le règne d'Auguste, le fondement de la validité des actes du prince. Sur cet ensemble, le prince avait à régler sa volonté, ce qui signifie sans doute que ses innovations n'étaient pas comprises comme telles, mais comme inscrites dans la tradition. Au plus haut de la hiérarchie normative était placée l'institutionnalité romaine en personne. La chose institutionnelle comme telle était proposée comme limite et fin de l'institution. $\grave{A}$ cette "chose » qui n'avait rien de métajuridique, puisqu'elle était intrinsèquement juridique, était assignée une position référentielle. La limite était pensée comme immanente, par réflexivité de la chose même. À une distance infinie, l'image de l'édifice du droit bornait illusoirement le champ ouvert à la volonté du monarque. Dédoublée

32. Ciceron, De orat., 3, 134 : la formule correspond ici, dans le domaine du droit privé, à la distinction traditionnelle du droit sacré et du droit civil, distinction d'une nature comparable à celle qui divise, dans le domaine du droit public, le droit sacré et sacerdotal d'un côté et le droit public à proprement parler, c'est-à-dire le droit des magistratures, de l'autre (P. Catalano, "La divisione del potere a Roma », Studi Grosso, 6, 1974, p. 667-691 et J. SCHEID, « Le prêtre et le magistrat. Réflexions sur les sacerdoces et le droit public à la fin de la République ", dans Des ordres à Rome, C. Nicolet éd., Paris, 1984, p. 243-280). Également part. or., 129, à propos de la partition générale du droit, où ius divinum semble recouvrir, plutôt que le droit sacré proprement dit, un droit d'origine divine, confondu plus ou moins avec l'équité naturelle (voir A. BERGER, R.E., 10, s.v. iurisprudentia, $1286 \mathrm{sq}$. et F. WiEACKER, Römische Rechtsgeschichte, 1, Munich, 1988, p. 492). La formule de la lex de imperio s'inscrit donc dans un ordre de division canonique où s'articulent institutions divines et humaines et, à l'intérieur de ces dernières, le droit public et privé (voir en ce sens, J.-J. Scheid, Romulus et ses frères. Le collège des frères arvales, modèle du culte public dans la Rome des empereurs, Ec. Fr. Rome, 1990, p. 271, n. 45).

33. Res de droit divin et de droit humain : Digeste, $1,8,1$, pr. et $43,1,1$ pr.; mariage : $D$., $23,1,1$. 
et dressée comme au-dessus d'elle-même, l'institution était érigée en Majesté de l'Institution ${ }^{34}$.

\section{LA GRANDEUR DE LA MAGISTRATURE}

L'idée romaine d'un statut propre à ce qui est supérieur appartient certainement et primordialement à la langue du droit public. Mais que sait-on de son origine? Peut-on dégager, de la très mince documentation disponible pour l'époque la plus ancienne, les premiers linéaments de son histoire juridique? Dans les premiers temps de la République, la suprématie revenait à la magistrature, et c'est à celle-ci, certainement, que fut d'abord réservée la position de la majesté. Certes, nos sources tardorépublicaines ne laissent plus apparaître, au premier rang, que la maiestas populi Romani. Au $\mathrm{I}^{\mathrm{er}}$ siècle avant notre ère, le peuple romain se détache comme son ultime détenteur. Il est devenu l'unique sujet d'une dignité de laquelle découlent et à laquelle participent toutes les hautes fonctions électives. Les charges politiques sont présentées comme de simples émanations de sa " grandeur », éléments du patrimoine collectif qui la constitue. À lire les orateurs ou les historiens des derniers temps de la République, on risque d'en rester à l'impression d'une sorte de délégation de la majesté aux magistrats qui l'auraient reçue en dépôt - comme si leur maiestas était seconde et dérivée d'un mandat électif ${ }^{35}$. Mais cette

34. Notons aussi que cette formulation de l'idée de limite est réservée à la charte constitutive qu'est la lex de imperio : elle n'est pas reprise dans la formulation des lois ordinaires. En outre, le prince incarnait la majesté : la contradiction entre sa maiestas et celle des institutions se résolvait dans l'idée d'une grandeur enchaînée à elle-même : en se soumettant de soimême aux lois, en observant ce qu'il avait prescrit, le souverain laissait apparaitre une majesté respectueuse d'elle-même (Sentences de Paul, 4, 5, 3 : « par une majesté égale à celle avec laquelle il les a faites, le prince doit obéir aux lois "; C.J., 1, 1, 14, lex " digna vox " de 429, « c'est par une loi digne de la majesté du prince régnant qu'est proclamé que le prince est lié aux lois "). En fait, l'aporie d'un prince soumis aux lois et législateur suprême ne peut être résolue en imaginant qu'il s'agirait de deux visions contraires qui se seraient succédé dans le temps (ainsi, P. Brunt, qui croit à un changement au temps de Caligula : « Lex de imperio Vespasiani ", Journal of Roman Studies, 1977, p. 95-114 ; F. LuCREzI, qui ne voit les choses changer qu'au III' siècle : Leges super principem. La monarchia costitutionale di Vespasiano, Naples, 1982, p. 198 sq. et " Al di sopra e al di sotto delle leggi ", dans Scritti Guarino, 2, Naples, 1984, p. 683 sq.). En réalité, la formulation de la lex de imperio contient les volontés impériales dans des limites non circonscrites, dont il est seul juge - ce dont me paraît rendre compte la formule de Dion Cassius $(53,28,2)$ à propos du droit conféré à Auguste, en 24, d'être délié des lois : " afin qu'il puisse être maître de lui-même et des lois, autokratôr heautou kai tôn nomôn. "

35. Au début du ir siècle av. J.-C., les rhéteurs incluent explicitement dans la majesté du peuple le statut de la magistrature et les suffrages (Rhétorique à Herennius, 2, 12, 17 et CicERON, De inventione, 2, 53 : « diminuer la majesté, c'est retrancher quelque chose de la dignité du peuple [...] ou de ceux à qui le peuple a conféré son pouvoir. ») Selon la lex Iulia, c'est un crime contre la "majesté du peuple Romain " de tuer " un magistrat du peuple Romain ou quiconque détiendra [i.e. par mandat du peuple] un imperium ou une potestas » (Digeste, 48, 
vue démocratique appartient à un passé relativement proche. Elle nous masque le rapport plus étroit qui existe originellement entre la magistrature et la majesté. Ces deux expressions juridiques appartiennent au même concept. Maior est à magister et magistratus ce que minor est à minister et ministerium : le plus et le moins grand servent à désigner le magistère du pouvoir et le ministère du petit personnel qui lui est affecté : le magistrat et les assistants du magistrat ${ }^{36}$. Mais en même temps, la notion concrète (l'individu en charge, le magistrat) ou abstraite (la charge en général, la magistrature) de la haute position qui est propre à l'exercice de la puissance se double de l'idée même de sa hauteur; le plus élevé reçoit un statut d'élévation qui l'isole : la majesté est l'état de supériorité du pouvoir. Si un tel concept a pu être formulé par le très ancien droit public, avant d'être rapporté au populus dont la notion lui est fondamentalement étrangère, il ne put qu'être réservé d'abord à l'institution qui, par son nom, impliquait l'idée d'une suprématie.

Il est d'autant moins expédient d'asseoir ce concept sur l'idée démocratique d'une supériorité distinctive du peuple que, les travaux d'A. Magdelain nous l'ont définitivement appris, l'idéologie de la souveraineté populaire est à Rome une formulation tardive et contraire aux structures profondes de son droit public. L'imperium y revêt un caractère originaire qui est érigé en dogme par la légende nationale de la fondation, puisque le pouvoir et l'espace où il se déploie sont inaugurés par Romulus avant que le peuple soit créé par lui ${ }^{37}$. Il se renouvelle chaque année au moment où le magistrat nouvellement investi fonde sur de nouveaux auspices la Ville, en même temps que son propre pouvoir ${ }^{38}$. Ce caractère se perpétue d'une manière qualifiée par Mommsen d'autarcique, à travers la procédure de nomination du consul par le consul qui le précède, sans que le choix électoral du peuple, qui vient se greffer sur

4 , 1). Salluste fait remonter la majesté du peuple à la première sécession de la plèbe (Jugurtha, 31, 17) et Trre-Lrve, à l'instauration du régime républicain $(2,7,7)$. La théorie d'une majesté dérivée de celle du peuple, qui l'aurait possédée de toute origine, représente un état tardo-républicain du droit et ne peut passer pour très ancienne, comme le prétend au contraire R. A. Bauman, op. cit. supra n. 16, p. 12. Quant à la théorie mommsénienne d'une maiestas originellement tribunicienne - et distincte de l'imperium des magistrats patriciens -, elle ne repose sur absolument aucune source (Le Droit pénal romain, op. cit. supra n. 1 , II, p. 234 sq.).

36. T. Mommsen, op. cit. supra n. 28,1, p. 8 sq. Magister est assez tôt tombé en désuétude dans la langue du droit public et ne s'emploie plus que pour désigner les présidents des collèges ou des confréries religieuses : mais sa position dans le collège sacerdotal est homologue de celle du magistrat dans la cité (voir J. SCHEID, op. cit. supra n. 32, p. 261 sq.).

37. T. Mommsen, op. cit. supra n. 28, I, p. 3 ; p. 90 sq. A. Magdelain, Recherches sur l' " imperium ". La loi curiate et les auspices d'investiture, Paris, 1968, p. 37 sq. ; "L'inauguration de l'Urbs et l'Imperium ", Mél. Ec. Fr. Rome, 1977, p. 11-29 = Études de droit romain, op. cit. supra n. 18, p. 209-228.

38. Recherches..., op. cit. supra n. 37, p. 39, 69; “ L'inauguration... ", art. cit. supra n. 37, p. 224. 
elle, en anéantisse jamais la signification purement translative ${ }^{39}$. Ce caractère se confirme enfin avec éclat dans le mécanisme typiquement républicain de l'interrègne, lorsque la vacance du pouvoir consulaire fait " remonter aux pères" et resurgir du sein des sénateurs patriciens anciens consuls, comme de leur source première, les auspices grâce auxquels, interroi après interroi, la vacance sera comblée jusqu'à la nomination d'un nouveau titulaire ${ }^{40}$. La magistrature se conçoit donc d'une manière autonome et l'organisation constitutionnelle évite de fonder la collation du pouvoir sur l'élection, même si l'élection est une condition préalable à l'investiture. Le populus, à Rome, ne fut pas au principe de l'imperium, lequel "planait éternellement au-dessus de lui " ${ }^{41}$. Par suite, l'idée chère aux orateurs et aux écrivains de la République tardive, selon laquelle les magistrats tiraient leur pouvoir d'un mandat du peuple, et relevaient par conséquent de lui quant à leur majesté, ne correspond pas aux mécanismes du droit ancien. La maiestas convient parfaitement, tout au contraire, à l'institution proprement hiérarchique de la magistratus. Elle en qualifie l'essence même.

L'annalistique républicaine avait conservé une représentation imagée de cette prévalence, sous la forme d'un épisode constitutionnel qu'elle situait à l'instauration même de la République, en 509, aussitôt après la chute des rois. Devant le peuple assemblé, Valerius Publicola ordonne de retirer les haches des faisceaux consulaires, les douze faisceaux de haches et de verges liées, portés par les douze licteurs dont les consuls se faisaient toujours et partout précéder en public, à la manière des rois étrusques. Dans la Ville, désormais, le magistrat supérieur ne serait plus précédé que par les verges et il renoncerait à déployer tout l'appareil de la puissance royale. Mieux, Publicola avait annoncé cette mesure par un geste encore plus radical. Devant le peuple, il avait fait incliner les faisceaux (summittere fasces), abaisser les insignes du pouvoir (summitere insigna imperii). Par cet aveu (confessio) avait été rendu manifeste, selon l'expression de Tite-Live, à quel point « la majesté du peuple et sa puissance étaient supérieures à celles du consul " : populi quam consulis maiestatem vimque maiorem. Le pouvoir plein et entier du roi n'était plus seulement divisé entre deux titulaires égaux, armés chacun des instruments royaux de la coercition capitale. Bien plus, par un acte divisé en deux séquences, ce pouvoir s'était de soi-même diminué. D'abord, il s'était incliné devant plus éminent que lui, acte de soumission. Puis il s'était privé des haches, acte d'amputation. Avec un sens juridique très

39. Staatsrecht, op. cit. supra n. 28 , I, p. 212 sq. Recherches..., op. cit. supra n. 37 , p. 34. 40. T. Mommsen, op. cit. supra n. 28, I, p. 646 sq. A. MAGDelain, « Auspicia ad patres redeunt ", dans Hommages Bayet, Paris, 1964 = Etudes, op. cit. supra n. 18, p. 341-383.

41. Expression de T. Mommsen, Abriss des römischen Staatsrechts, Leipzig, 1893, p. 306. 
sûr, la tradition respecte l'enchaînement de l'inclinaison puis du retrait. Le premier geste est distinct du second, mais il l'anticipe et le rend nécessaire. L'aveu récognitif de majesté appelle un abandon du droit de vie et de mort, de même que, en sens inverse, la cession de l'ultime attribut de la puissance présuppose une reconnaissance de la majesté : le cercle logique se boucle avec l'ordre du récit. Or ce dernier geste préside à l'institution toute nouvelle de l'appel au peuple : le populus statuera désormais en dernier lieu sur la vie et sur la mort. Avec la première loi sur la provocatio ad populum, le lieu ultime où réside la puissance de mort s'élève au-dessus du consul. Il se déplace après que le consul s'est plié devant la maiestas maior des Romains. Ou bien, dit encore Forus, après qu'il a résolu d' " augmenter la maiestas d'un peuple libre ", ad augendam liberi populi maiestatem - ce que Plutarque comprend, puisque la majesté est inconnue en grec, comme un « rehaussement du prestige de la démocratie ${ }^{42}$.

Abaissement des symboles de l'imperium hérités de l'appareil de la terreur royale et primauté de la "majesté et de la puissance du peuple " ne font qu'un. À l'origine mythique de la liberté romaine (c'est à la libertas que, dans le $\mathrm{De}$ Republica, Cicéron réfère le retrait des haches et l'inclinaison des faisceaux), il y a la révérence du pouvoir consulaire et son volontaire effacement devant une maiestas maior. Seulement, nous savons bien que ce geste est une fiction anachronique et la diminution de la magistrature face au peuple une lointaine anticipation. C'est en 300, selon la datation la plus vraisemblablement proposée, qu'est instituée la provocatio ad populum. Jusqu'à cette date, la magistrature supérieure détient et exerce un pouvoir répressif intact, avec pour ultime attribut le

42. Trte-Live, 2, 7, 7 ; Florus, 1, 9, 4 ; Ciceron, De Republica, 2, 53, pour l'inclinaison des faisceaux (P. VALERIUS, "fasces primus demitti jussit") et 2, 55, pour le retrait des haches (" secures de fascibus demi iussit "); également Valére Maxime, 4, 1, 1 et Plutarque, Publicola, 10, 7 : « lorsqu'il s'avançait devant l'assemblée, il abaissait et inclinait les faisceaux euxmêmes, rehaussant ainsi le prestige de la démocratie " - méga poiôn to proschèma tès dèmokratias. L'abaissement des faisceaux - fasces demittere ou summittere - est distinct du retrait des haches - fasces demere - (réf. in B. KUBLER, RE, XIII, 1, c. 513), quoique dans le récit fondateur le premier geste annonce le second. Ce dernier geste signifie techniquement l'abandon de la coercition capitale à Rome (T. Mommsen, op. cit. supra n. 28, 1, p. 380 ; A. Magdelain, Etudes, op. cit. supra n. 18, p. 549) alors que le premier est un hommage symbolique à une majesté supérieure : on le voit bien, sous la République, lorsque le magistrat incline ses faisceaux en présence d'un magistrat supérieur à lui (T. MoMMSEN, op. cit. supra n. 28, 1, p. 378); de même, sous le principat, lorsque les magistrats et les hauts fonctionnaires détenteurs d'imperium marquent ainsi leur infériorité devant le princeps ou devant les membres de sa famille (Velleius Paterculus, 2, 99, 4). À l'époque chrétienne, le renversement de majesté s'opère lorsqu'on abaisse les faisceaux devant les reliques des saints (PRUDENCE, c. Symmaque, I, 557, 564). Sous l'Empire, l'inclinaison des faisceaux en hommage à la souveraineté du peuple a disparu. En revanche, il arrive que le prince fasse génuflexion en présence de la multitude, notamment dans l'amphithéâtre : A. Alföld, Die monarchische Repräsentation im römischen Kaiserreich, Darmstadt, 1970, p. 64 sq. 
droit de faire décapiter un citoyen à la hache. Après cette date, la coercition capitale du magistrat est suspendue dans la Ville par l'appel au peuple. Les haches ne sont plus un instrument régulier de l'imperium et leur usage incontrôlé cesse à l'intérieur du périmètre urbain. Dans cet espace privilégié, elles sont retirées des faisceaux. Peut-être aussi les faisceaux sont-ils inclinés lors des assemblées du peuple, mais nous n'en avons pas d'autre trace que le geste fondateur de Publicola. Par rétrojection d'une réforme démocratique dont les incidences éventuelles sur la langue du droit public n'ont pas pu se produire avant le cours du $\mathrm{III}^{\mathrm{e}}$ siècle, les annalistes républicains ont mis en scène le spectacle d'une réduction primordiale de la puissance. Ils enseignent que le premier acte de la magistrature fut de renoncer à sa maiestas, en instaurant dès le principe une supériorité supérieure à la sienne. Seulement, par ce renversement même, ils témoignent aussi qu'ils connaissaient ou qu'ils supposaient un état antérieur de la majesté. La fiction table sur l'hypothèse qu'au départ elle se reconnaissait aux marques terrifiantes de l'imperium $^{43}$.

Cette affinité se laisse deviner dans l'étymologie. Mais l'histoire n'en a rien conservé, sinon quelques épisodes qui révèlent chez les annalistes l'intuition d'une relation primordiale entre la puissance de vie et de mort du magistrat supérieur et sa majesté : le dictateur Appius Claudius menace des verges et des haches la foule des citoyens qui bousculent ses licteurs, et proclame que «le droit sur le dos et sur la vie de chacun appartient à celui-là seul dont on aura outragé la maiestas "; le consul Manlius Torquatus fait prévaloir sur l'affection paternelle « le droit dę la majesté et du pouvoir ", ius maiestatis atque imperii, et ordonne que l'on décapite son fils; ou bien encore, les consuls s'efforcent de supprimer, dès sa légalisation, le tribunat de la plèbe, parce qu'ils voient, dans cet instrument de défense des citoyens contre l'imperium, une machine de guerre « pour diminuer leur propre majesté ». Mais ces expressions sont de Tite-Live, de Cicéron, ou de leurs sources annalistiques : rien n'en garantit la valeur pour une époque beaucoup plus ancienne. Elles montrent seulement, avec l'épisode de Valerius Publicola, que l'on se représentait, sous la République tardive, un passé où la maiestas du magistrat n'était pas encore une émanation du populus Romanus; on supposait qu'elle avait qualifié primitivement la prééminence du magis-

43. Sur la chronologie de la provocatio ad populum et sur son lien avec la coercition, plutôt qu'avec la juridiction, voir la vigoureuse démonstration d'A. MAGDELAIN, « De la coercition capitale du magistrat supérieur au tribunal du peuple ", Labeo, 1987, p. 139-166 = Études, op. cit. supra n. 18, p. 539-565; dans un sens opposé, M. HumberT, “ Le Tribunat de la plèbe et le Tribunal du peuple : remarques sur l'histoire de la provocatio ad populum ", Mél. Ec. Fr. de Rome, 1988, p. 431-503, qui fait remonter la provocatio à 509 - et même à l'époque royale - , mais accepte de dater l'abandon des haches en 300 av. J.-C. 
trat supérieur, lorsqu'il exerçait la coercition hors contrôle des tribuns de la plèbe et sans recours au peuple : soit parce que ce droit n'existait pas encore (Valerius), soit parce qu'il était suspendu en période de dictature (Claudius), soit parce qu'il ne s'appliquait pas à l'armée (Manlius) ${ }^{44}$.

L'histoire du mot magistratus lui-même est d'ailleurs mal connue : comment retracer dès lors l'histoire de son association primitive avec maiestas? Son ancienneté est pourtant certaine. L'atteste déjà - en dehors du magister d'origine étrusque et, à Rome, du « maître " des fantassins et du " maître " de cavalerie - une inscription archaïque, retranscrite vers le commencement de l'Empire sur la colonne rostrale de Duilius à Rome : il y est question d'un maximos macistratos. Or maximus, dans la langue du droit public du premier âge républicain, qualifie précisément la magistrature armée de la toute-puissance capitale. On appelait praetor maximus, aux $v^{\varepsilon}$ et $v^{\varepsilon}$ siècles, celui des deux consuls (et non pas, comme on l'a souvent supposé, le premier d'un collège d'au moins trois) auquel revenait à tour de rôle le plein exercice de l'imperium. L'entier pouvoir était distribué alternativement, selon le mécanisme du roulement des faisceaux. Le magistrat était maximus pendant son délai de puissance capitale, pendant le temps seulement où, en alternance avec son collègue, il détenait les verges pour fouetter à sang et les haches pour décapiter. La rotation des instruments du supplice portait ainsi à son ultime degré l'idée qui s'attachait à une fonction désignée elle-même d'un nom, formé sur la même racine que maior et maiestas, qui la majorait, en même temps que cette fonction était en sa plénitude qualifiée de "maximale $"$ "45.

Il est peut-être un autre indice de l'ancienneté et de la signification du lien qui unit la magistrature à maiestas. En droit public, le général victorieux avait droit au triomphe seulement si la guerre avait été conduite sous ses auspices et pendant qu'il était magistrat. Au moment où il gravit le Capitole, orné des mêmes insignes que Juppiter, le roi dieu, et qu'il se rend à son sanctuaire, monté sur un quadrige de chevaux blancs et le visage passé au rouge comme l'est celui du dieu lui-même, dont il est à ce moment la vivante image, l'imperator célèbre une victoire affectée à son seul titre de magistrat. Le rite donne leur éclat à des hauts faits statutairement accomplis, selon la norme, in magistratu. À trois reprises, au cours du III siècle, on voit le Sénat invoquer la règle ancestrale pour refuser l'honneur du triomphe à qui avait remporté la victoire sine magistratu. Comme l'a démontré $H$. Versnel, cette règle implique qu'il ne suffisait

44. Appius Claudius: Trte-Live, 2, 29, 12 : penes unum illum esse cuius maiestatem violaverit. Torquatus : Cićron, Fin. 1, 23... Tribunat et atteinte à la majesté consulaire : TrreLIVE, 3, $24,9$.

45. Sur praetor maximus, cf. supra $\mathrm{n} .18$. 
pas d'être investi d'un imperium pour triompher; mais qu'il fallait en plus détenir une charge qui le comportait statutairement. Ce qui excluait, par exemple, les simples " particuliers pourvus d'un commandement " (privati cum imperio): mais aussi les tribuns militaires, officiers qui n'avaient pas rang de magistrats - même si l'on avait adjoint la puissance consulaire à leur titre de tribun, qui ne la comportait pas normalement. Les " tribuns militaires à puissance consulaire " détenaient une puissance sans le titre (puisqu'ils n'étaient pas consuls) et un titre dépourvu de la puissance (puisqu'ils n'étaient que tribuns) : tenant lieu de magistrats sans l'honneur du rang, ils restaient inaptes à triompher. $\grave{A}$ l'inverse, la victoire du triomphateur illustrait la maiestas non de sa personne, mais de la dignité qu'il occupait ${ }^{46}$.

Dans cette norme du très ancien droit public est exaltée l'institution du pouvoir plutôt que son exercice. Voilà qui permet déjà de faire remonter l'histoire de la magistrature bien au-delà des premières attestations du mot. Mais voilà surtout qui aide à comprendre mieux le rapport qui lie primitivement cette notion à celle de majesté. Car à travers cette règle du droit archaïque du triomphe, la magistrature apparaît comme un statut régulier, comme un état durable de la puissance. La puissance doit son statut d'élévation, son état de supériorité à la permanence d'une inscription institutionnelle : telle est la condition abstraite de la magistratus et telle est sans doute celle de la maiestas qui lui correspond. C'est une construction proprement romaine et d'une importance cruciale pour l'intelligence de la structure occidentale du pouvoir, que l'idée de son élévation statutaire ait été pensée et organisée isolément de sa réalité affective, par une imputation de la grandeur à la pérennité d'un office constitué.

Voilà bien l'essentiel : l'immobilisation du pouvoir sous une qualification juridique constante, la présupposition institutionnelle de la puissance, sa présence continue dans l'architecture du droit. Cette propriété fut originellement nécessaire à la prééminence inscrite dans les noms de la magistrature et de la majesté. Culmination qui avait pour marque, certes, l'attribut ultime du droit de vie et de mort. Mais la grandeur d'un tel attribut était d'être maintenu comme institution. Alors nous apparaît

46. Triomphe nécessairement in magistratu : voir H. Versnel, Triumphus. An Inquiry into the Origin, Development and Meaning of the Roman Triumph, Leiden, 1970, p. 186 sq. Maiestas du triomphateur : TrTE-Lrve, 45, 40, 4 (triomphe de Paul Emile en 167); cf. 5, 41,8, à propos des anciens triomphateurs : praeter ornatum habitumque humano angustiorem maiestate etiam [...] simillimos dis; OvDE, Fastes, 5, 51-52. Sur l'incarnation de Juppiter pendant le triomphe, voir L. Deubner, « Die Tracht des römischen Triumphators ", Hermes, 1934, p. 316-323; G. Dumkzil, La Religion romaine archaïque, Paris, 1967, p. 285 sq. ; J. SCHEID, "Le flamine de Juppiter, les Vestales et le général triomphant ", dans Le Corps des dieux. Le Temps de la réflexion, $\mathrm{n}^{\circ}$ 7, Paris, 1986, p. 213-229. 
dans sa plénitude inentamée, et proche encore de sa valeur étymologique, la maiestas magistratus, une majesté que les Romains faisaient remonter aux rois ${ }^{47}$.

Dans nos sources, cependant, tout commence avec la maiestas du peuple Romain. C'est elle qui, sous l'Empire, servira de modèle au statut d'inviolabilité du prince, qui l'a monopolisée très tôt à son profit. C'est elle aussi qui nous apparaît le plus nettement sous la République, sous une forme juridiquement constituée. Sa préhistoire impératorienne et consulaire ne nous est pas directement accessible. Elle se laisse à peine deviner à travers quelques indices d'où l'on peut induire qu'elle avait rehaussé dans un premier temps le pouvoir hérité des rois face aux autres composantes de la cité. Cependant, c'est sous cette forme seconde que nous commençons à la connaître vraiment, à partir $\mathrm{du} \mathrm{III}^{\mathrm{e}}$ siècle avant notre ère. Ses plus anciennes traces documentaires montrent qu'elle est devenue le propre de la cité prise comme un tout. Mais il est impossible de dire si la première apparition de la maiestas du populus est la contrepartie de la dégradation de la magistrature supérieure face à lui. L'on peut seulement supposer, en suivant la reconstruction d'A. Magdelain, que la qualification de maximus donnée à l'assemblée des centuries n'est pas antérieure à l'introduction de l'appel au peuple en 300 av. J.-C., et que son élévation dans l'échelle des pouvoirs est corrélative de l'abaisse-

47. Dans Trre-Lrve, c'est-à-dire dans l'essentiel de ce qui nous reste de l'annalistique républicaine, la Majesté est presque toujours attachée à la magistrature : ainsi $2,36,3$, verecundia maiestatis magistratuum $; 5,41,8$ : maiestas des anciens magistrats curules, objets de vénération (venerabundi intuebantur);24, 44, 10, maiestas de Fabius Cunctator sur son fils consul dont il est le légat et que les licteurs n'osent pas faire descendre de son cheval, "verecundia maiestatis eius" : cette anecdote ne permet pas de dissocier la majesté de la puissance consulaire, comme le voudrait H. Hellegouar'CH, op. cit. supra n. 2, p. 317, car nous avons affaire ici à l'une des multiples illustrations du topos de la supériorité du père sur son fils mêrme magistrat (Y. ThomAs, « Droit domestique et droit politique à Rome », MEFRA, 2, 1982 , p. 567 sq.) ; tout au contraire, l'exemplum confirme la régularité de la majesté consulaire, que le fils finit par faire respecter à son père lui-même, à la plus grande joie de celui-ci. Valère MAXime, 1, 1, 9 : summa maiestas du magistratus (cf. LACTANCE , Inst. Div., 1, 21, 47) ; VITRUVE, 6, 5, 2 ; SUETONE, Tibère, 30 : Tibère rend aux magistrats et au sénat leur maiestas pristina et leur puissance. Majesté primordiale des rois : LuCréce, 5, v. 113 sq.; Ovide, Fastes, 5, v. 47 sq.; Justin (Trogue Pompée), Histoire Philippique, 1, 1 ; Scholies de Bobbio, p. 94, Hildebrandot 1, 19. En faveur d'une extension tardive de la notion de majesté à la magistrature, voir cependant H. G. GUNDEL, art. cit. supra n. 3, p. 308 sq. et « Der Begriff Maiestas im Denken der Augusteischen Zeit ", dans Saeculum Augustum I, G. Binder éd. Darmstadt, 1963, p. 115 sq. 
ment du magistrat. En effet, par deux mouvements inverses, alors que le comitiatus monte au degré supérieur, en recevant la qualité de comitiatus maximus, le niveau de la magistrature descend, lui, de maximus à maior. Les faisceaux, désormais dégarnis dans la Ville, reviennent alternativement à celui des deux consuls que l'on ne désigne plus comme maximus mais comme maior. De même, les auspices du magistrat le plus élevé passent du rang maxime au rang majeur. Autant d'indices montrant qu'il a perdu par rapport aux autres organes de la cité sa position suprême ${ }^{48}$. Cette redistribution des échelles de la grandeur dans la langue du droit public se produit sans doute au cours du nir siècle.

Explique-t-elle le déplacement de majesté qui a abouti à la maiestas populi? Une fois de plus, nous buttons sur les lacunes d'une documentation drastiquement clairsemée. Car la majesté qui se laisse atteindre à travers de rares documents, aux III $^{\mathrm{e}}$ et II $^{\mathrm{e}}$ siècles av. J.-C., ne s'évalue plus sur le même plan. La suprématie du populus Romanus est alors confrontée non pas aux magistrats, à l'institution du pouvoir, mais aux autres cités, au monde extérieur dominé par Rome. La maiestas populi Romani fait bien son entrée dans les sources de cette époque, mais c'est pour définir un rapport d'hégémonie cosmopolitique. De sa signification à l'égard de la magistrature, à l'intérieur d'un rapport de droit public interne, nous n'avons encore aucun témoignage sûr. En sorte que la question de son lien d'origine avec le renversement de la souveraineté capitale au III $^{e}$ siècle est sans réponse, même si quelques indices et si, surtout, l'histoire de la majesté dans le long terme laissent penser qu'il faudrait conduire l'analyse sur ce terrain. Beaucoup plus tard, au $\mathrm{I}^{\text {er }}$ siècle avant notre ère, elle se prête à une approche renouvelée de la hiérarchie entre les organes et les pouvoirs. Alors, mais pas avant, commence pour nous l'histoire juridique interne de la Grandeur du peuple Romain, grandeur évaluée et sanctionnée à l'intérieur de l'entité politique.

En attendant, la maiestas des $\mathrm{III}^{\mathrm{e}}$ et $\mathrm{II}^{\mathrm{e}}$ siècles av. J.-C. nous apparaît uniquement sous l'aspect d'un rapport d'inégalité entre Rome et les cités sujettes. Les « traités inégaux » qui leur étaient imposés contenaient une clause de réserve d'hégémonie. Le premier document remonte à 189 : la ligue des Étoliens y est obligée de " préserver sans ruse le pouvoir et la majesté du peuple Romain ». Peut-être de telles clauses avaient-elles été

48. A. Magdelain, « Praetor maximus et Provocatio ad populum ", dans Etudes de droit romain, op. cit. supra n. 18, p. 567 sq. A. GuARINo, La Rivoluzione della plebe, Naples, 1975, p. 319 sq. E. GABBA revient à la conception traditionnelle d'un comitiatus maximus présent dès la loi des douze Tables et donne à cette expression le sens purement factuel de « très large rassemblement ", hypothèse difficilement acceptable (" Maximus comitiatus ", Athenaeum, 1987, p. 203 sq. ; voir la critique de M. Humbert, art. cit. supra n. 43, p. 467, qui croit néanmoins à l'authenticité du verset décemviral affirmant la souveraineté de l'assemblée populaire en matière capitale). 
imposées auparavant, par exemple à l'égard des peuples italiques. L'usage en tout cas s'en était confirmé au cours du temps. Nous la retrouvons dans un traité avec Gadès en 78 et dans un traité avec Mytilène en 25. En outre, sa portée s'était sensiblement modifiée dans la durée. Elle avait d'abord représenté un dispositif de sujétion, accompagné de certaines mesures restrictives d'indépendance; par la suite, elle était devenue une simple expression de l'appartenance des cités au monde romain, la prise en compte du fait que leur place était maintenant dans l'Empire. À la clause de majesté pouvaient dès lors s'ajouter un certain nombre de privilèges unilatéralement consentis par la puissance romaine, qui fixait divers types de statuts garantissant une relative indépendance à l'intérieur d'un monde qu'elle dominait ${ }^{49}$. D'où, peut-être, la formule édulcorée qui se lit en 78 dans le traité de Gadès et que le juriste Proculus, au ${ }^{\text {er }}$ siècle de notre ère, interprétait comme courante : l'engagement n'y était plus que de "préserver obligeamment la majesté " de Rome ${ }^{50}$. L'idée d'hégémonie s'était en quelque sorte régularisée et pacifiée.

En 249 av. J.-C., lors des premiers jeux séculaires, des prières publiques avaient été adressées aux dieux pour favoriser « la domination et la majesté " des Romains. Le formulaire de cette prière nous est parvenu à travers celui des jeux de 17 av. J.-C., rédigé sans doute d'après l'original par le juriconsulte Ateius Capito, grand technicien du droit public et du droit sacral sous Auguste. Selon la prescription rituelle, le consul devait dicter à cent dix matrones, engagées à célébrer la perpétuité romaine, les verba qu'il fallait adresser aux dieux, et particulièrement à Junon Reine, pour sa croissante prospérité : «nous te demandons et nous te prions d'augmenter l'imperium et la maiestas du peuple Romain des Quirites, dans la guerre comme dans la paix $"$ " 5 . La grandeur qui se

49. Je suis ici l'analyse de J. L. Ferrary, «Traités et domination romaine dans le monde hellénique ", dans I Trattati nel mondo antico Forma, ideologia, funzione, L. CANFORA, M. Liverani, C. Zaccagnini éds, Rome, 1991, p. 217-235 (p. 231 sq., sur le traité épigraphique de Mytilène). La clause du traité imposé à la ligue des Etoliens se lit dans TriteLrve, 38, 11, 2 : imperium maiestatemque populi Romani gens Aetolorum conservato sine dolo malo = PolyBe, 21, 32, 3, où imperium maiestasque est traduit par archè kai dynastéia; sur cette traduction, voir H. G. Gundel, « Der Begriff Maiestas ", op. cit. supra n. 47, p. 295 sq. et M. Dubuisson, Le Latin de Polybe, Paris, 1985, p. 92 sq. ; cf. J. L. Ferrary, op. cit. supra, p. 227. Traité de Gadès : Cickron, Pro Balbo, 35.

50. Maiestatem populi Romani comiter conservare : CICERON, Pro Balbo, loc. cit. supra n. 49, et Proculus, Digeste, $49,15,7,1$. Sur l'antériorité de la formule avec imperium maiestasque sur celle qui ne comporte que maiestas, voir J. L. FerRarY, op. cit. supra n. 49, p. 227 , n. 25, qui cite son réemploi dans le sénatus-consulte ultime de 100 av. J.-C. (CicEron, Pro Rabirio perd., 20 : " ut imperium populi Romani maiestasque conservaretur "), texte auquel on peut ajouter la formule encore plus ancienne des jeux séculaires (voir infra n. 51).

51. CIL , 6, 32323 = Dessau, 5050, 127. Sur le rôle de Capito dans l'élaboration des jeux séculaires de 17 av. J.-C., R. A. Bauman, Lawyers and Politics in the Early Roman Empire, Munich, 1989, p. 35. La liaison imperium maiestas $p$. $R$. Quiritium est formulaire et figure régulièrement dans les actes des jeux séculaires qui ont été conservés épigraphiquement, ainsi dans ceux de Septime Sévère en 204 ap. J.-C. (CIL, 6, 32328, 4, 7; 4, 11; 4, 50; 4, 56, avec le 
proclame dans une telle formule est celle, ouvertement, de la cité prise comme un tout. Cependant, elle ne s'affirme pas à l'encontre d'une cité particulière, comme dans la clause des traités inégaux, mais d'une manière absolue par rapport au monde. On songe à la prière qui clôturait le lustre tous les cinq ans, telle que la conservaient encore au commencement de notre ère les documents publics de la censure : « Dieux immortels, faites que les affaires du peuple Romain s'améliorent et s'amplifient ", res populi Romani meliores amplioresque. On songe également, pour nous en tenir aux formulaires officiels, à telle clause inscrite dans l'exposé des motifs d'un senatus-consulte de 58 av. J.-C. sur les privilèges fiscaux accordés à l'île de Délos : " attendu que la situation de la dignité et de la majesté du peuple Romain a été administrée de la façon la plus admirable, son empire agrandi, la paix assurée à travers le monde... "; supériorité où culmine une unique cité au-dessus de toutes les autres au point que sa suprématie, pensée moins en termes de relation, désormais, que comme une condition juridique durable, un état qui se perpétue en s'administrant, s'incorpore à Rome même en devenant comme une qualité constitutive de son essence ${ }^{52}$.

Aux alentours de 250 av. J.-C. est formulée la notion d'une majesté vouée à s'étendre indéfiniment. L'Empire et l'hégémonie des Romains sont mis sous le signe d'une augmentation, d'une amplification croissantes, dont le vœu doit se renouveler dans la suite des temps : augere imperium maiestatemque. Vers le milieu du u' siècle apparaît l'idée d'une domination étendue à l'ensemble du monde, et cette idée trouvera au I $^{\text {er }}$ siècle sa formule définitive dans la figure d'un imperium orbis terrae, qui était déjà un topos de rhéteur dans les années 90 av. J.-C. Un très

commentaire d'E. Dienl, dans Rheinisches Museum, 83, 1934, p. 255-272 et 349-372). H. Gundel, art. cit. supra n. 3, p. 302, n. 1, attribue cette formule à l'époque d'Auguste. Pourtant, à l'appui de précédents plus anciens, on peut évoquer, en dehors des exemples que Diehl tire de deux passages de Tite-Live, et qui ne reposent peut-être pas sur des documents authentiques, d'abord la clause des traités inégaux, telle que la reproduisent, pour le traité de 189 avec les Etoliens, Tite-Live et Polybe, ensuite le sénatus-consulte ultime de 100 av. J.-C. (supra n. 50). D'imperium maiestasque, on peut rapprocher aussi, dans des contextes internationaux, populi Romani ius maiestasque (par ex., César, Bellum Alexandrinum, 34, 2), voire vis maiestasque populi Romani (Trme-Lrve, 26, 24, 7; cf. 2, 7, 7, utilisé dans un contexte des rapports politiques internes).

52. Prière de clôture du lustre : Valére Maxime, 4, 1, 10, à propos de la censure de Scipion Emilen en 142 av. J.-C. Lex Gabinia de Delo insula, CIL, 1, 2, 2500, 1.18 sq., à lire aussi dans l'édition publiée sous la direction de C. Nicolet, Insula Sacra. La loi Gabinia Calpurnia de Delos, Ec. Fr. de Rome, 1980. Dans cette nouvelle édition, P. Moreau propose de restituer « dignitatis maiestatis < que sit re publica pulce> rrume administrata... ", ce qui suppose une proposition infinitive sujet introduite par le génitif maiestatis est, et séparée de ce génitif par une série d'ablatifs absolus. Je continue de préférer l'ancienne restitution de Durrbach et Lommatzsch, dignitatis maiestatis <que causa pulce> rrume administrata..., qui rend compte plus simplement du génitif. De l' "état de la majesté », " maiestatis causa", on peut rapprocher, quant au sens, l'expression "condicio maiestatis" (par exemple, SÉnĖQue le Rhéteur, Controverses, 9, 2, 25). 
beau livre de J. L. Ferrary a montré quel extraordinaire répertoire de thèmes idéologiques la philosophie grecque avait constitué pour l'expansionnisme romain du dernier siècle de la République. Certains (ainsi Philus, au troisième livre du De Republica) reprirent à leur compte la doctrine, issue d'Aristote et développée par des scholarques de la seconde Académie, notamment par Clitomaque, d'une tendance naturelle des individus et des peuples à s'abandonner à leur appétit de puissance, à élargir sans cesse le cercle de leurs conquêtes, à donner libre cours aux forces vitales qui les emportent loin de leurs domaines, sans nul souci du juste et de l'injuste. D'autres, sans doute en plus grand nombre parmi les milieux dirigeants, embrassaient la thèse contraire de la justification de l'empire par la guerre juste, ou prétendaient défendre la liberté des Grecs asservis par les monarques, ou bien encore invoquaient le consentement des cités et des nations ${ }^{53}$. Cependant, quels qu'aient été ses fondements idéologiques, l'empire grandissant de Rome avait trouvé dans son état de majesté une expression officielle de sa permanente croissance, une qualification de ses constants progrès, une formule propre à saisir la conservation de son essence par une amplification qui le maintenait en état de toujours plus grande supériorité.

La majesté du peuple Romain avait été très tôt conçue comme une grandeur en puissance de mouvement. Mais ce fut bientôt un mouvement pensé comme un état, un développement présupposé par une norme constante. La dynamique impérialiste se fixa dans une référence solennelle à la majesté de l'empire, notion où s'affirmait la marche continuelle de la conquête, puisque l'empire ne comportait pas l'idée de limite, que l'orbe de la terre se présentait comme son domaine virtuel et que les frontières en étaient par hypothèse toujours avancées (propagare fines), mais où en même temps l'idée de propagation expansionniste était figée comme en un monument glorieux. Maiestas imperii : la formule nous est attestée pour la première fois dans un texte de Cicéron en 80 , où elle est dite être échue avec la République et l'univers tout entier à Sylla, qui l'a obtenue par les armes et consolidée par les lois - l'on pense déjà à la "majesté ornée par les armes et armée par les lois" de la constitution Imperatoriam maiestatem de Justinien. Dans la loi épigraphique Calpurnia Gabinia de 59, de même, l' « administration de la majesté " implique une sorte de capitalisation de ses progrès et va de pair avec l" " amplification de l'empire " et la propagation de la " paix à travers l'orbis terrarum ". Dans l'historiographie tardo-républicaine, chez Salluste par exemple, des princes étrangers l'invoquent pour obtenir le secours des

53. J. L. Ferrary, Philhellénisme et impérialisme. Aspects de la conquête romaine du monde hellénistique, Ec. Fr. Rome, 1988. 
légions contre les guerres expansionnistes de leurs rivaux. Cicéron, César attachent son sort à celui des victoires romaines ${ }^{54}$. Elle est pensée comme une situation d'hégémonie arrêtée sur sa croissance, comme une position de suprématie maintenue par sa constante élévation : sa conservation réside dans son cumul et son cumul se capitalise en formules achevées.

Peut-être n'a-t-on pas assez souligné, ou pas accordé suffisamment d'importance au fait que l'idée même d'une augmentation de son empire, bien au-delà de sa portée idéologique, a fini par s'intégrer à la structure politique du peuple Romain, par se convertir en régulations permanentes. Entre la fin de la République et le commencement de l'Empire, elle s'affirme comme une donnée nécessaire et continue, abstraction faite de sa vérité. Cette idée se rattache bien sûr aux réalités de l'impérialisme, mais son importance ne tient pas tant à ce qu'elle reflète qu'à ce qu'elle finit par signifier en matière d'institutions. Il est déjà notable que l'imperium ait pu désigner aussi une forme d'état, l'étendue de la domination prêtant son nom à la forme de l'existence politique elle-même - indice terminologique sûr d'un défaut de séparation nettement pensée entre l'intérieur et l'extérieur, ce qui devrait conduire à s'interroger sur l'intérêt qu'il y a à appliquer l'idée étatique à Rome, en dehors d'une simple commodité de langage ${ }^{55}$. Il faut prendre au sérieux également, c'est-àdire au pied de la lettre, l'équivalence que des textes tardo-républicains et augustéens commencent à postuler entre urbs et orbis, entre la Ville et le monde ${ }^{56}$ : derrière l'apparence d'une association libre, le jeu verbal

54. CicÉron, Pro Roscio Amerino, 131 : cum (L. Sulla) solus rem publicam regeret orbemque terrarum gubernaret imperique maiestatem, quam armis reciperat, iam legibus confirmaret. SAlluste, Jugurtha, 14, 7 et 24, 10 : discours et lettre d'Adherbal au Sénat. Cesar, Bellum Gallicum, 7, 13, 3 et Bellum Alexandrinum, 34, 2, dans un contexte de guerre civile.

55. On ne s'est pas encore suffisamment avisé qu'imperium se détache très tôt de ses déterminations concrètes (la domination, l'étendue où elle s'exerce) pour se confondre avec l'entité politique elle-même, considérée abstraitement. On le voit déjà dans une harangue de Scipion Nasica en 133 av. J.-C., VAL. MAX., 3, 2, 17, où « ruiner l'Etat Romain (Imperium Romanum) en respectant les lois " équivaut à « ruiner la République », dans un contexte de guerres civiles. De même encore, dans tel discours d'Aemilius Scaurus en 89, VAL. MAX., 3, 7 , 8 , où « trahir l'État " se dit tour à tour prodere rem publicam et prodere imperium populi Romani. Également, une formule telle que « les droits propres à la cité et à l'empire " (Cic., De oratore, I, 204) sert à désigner les droits publics inscrits dans la tradition, etc.

56. Sur orbis terrarum en général, T. MoMMSEN, op. cit. supra n. 28, III, p. 827, qui donne les principales références d'époque républicaine, à compléter par J. Voor, « Orbis Romanus ", 1929, repris dans Vom Reichsgedanken der Römer, Leipzig, 1942, p. 170-207; P. BRUNT, "Laus imperii », dans Imperialism in the Ancient World, P. Garnsey et C. WhItTAKER éds, Cambridge, 1978, p. 168 sq. ; C. Nicolet, L'Inventaire du monde. Géographie et politique aux origines de l'Empire romain, Paris, 1988, p. 41 sq. Point de vue du droit sacré (avec une référence intéressante à Frontin, Grom., Lachman, p. 27) dans P. Catalano, "Aspetti spaziali del sistema giuridico-religioso romano ", $A N R W, 16,1,1978$, p. 550 sq. Les sources juridiques ont été réunies par F. LANCIOTn, " Lo spazio romano nella terminologia delle fonte giuridiche giustinianee in lingua latina ", dans Popoli e spazio romano tra diritto e profezia, Rome, 1986, p. 351-363, avec d'intéressantes remarques sur l'impossibilité de penser un état territorial à Rome. Sources géographiques tardives dans C. MoLe, « La ter- 
exploite en réalité le sens le plus fort du mot, puisque orbis désignait aussi, par métaphore, le cercle du sillon où commençait la ville, le circuit - le pomerium - qui la ceinturait, et puisqu'un antiquaire comme Varron, avec toutes les apparences de la rigueur, s'appuyait sur l'autorité du rite de fondation pour rattacher le nom de la ville à celui du cercle, orbis, qui l'entourait : $a b$ orbe urbes $^{57}$. L'image du cercle sert alors à penser l'inclusion du monde dans l'Urbs qui l'a conquis, mais cette représentation trouve elle-même appui dans la réalité du droit. Par exemple, le prince reçoit de la lex de imperio la prérogative de repousser l'enceinte (proferre promovere pomerium) qui délimite le sol urbain primordial, sol béni par les auspices de fondation et sol religieusement protégé, toutes les fois qu'il ajoute de nouvelles provinces à l'empire et qu'il en « porte en avant les frontières " (proferre fines), qu'il en " augmente les limites" (augere fines) : en sorte que, dans le principe, l'élargissement de l'orbe romain se marque par une redéfinition de l'Urbs et que le développement des confins a pour symbole une augmentation du centre ${ }^{58}$. Mais d'autres mécanismes juridiques donnent consistance à cette figure, où il ne faut pas hésiter à voir une équiparation. Signalons seulement celle qu'établit le droit pénal, lorsqu'il inclut dans tout territoire interdit de séjour le périmètre de Rome, parce que, disent les textes, Rome est partout : for-

minologia dello spazio romano nelle fonti geografiche tardo antiche ", ibid., p. 321-350. Sur urbs $/$ orbis, voir P. Catalano, art. cit. supra, p. 550 et A. Mastino, "Orbis, kosmos, oikouménè : Aspetti spaziali dell'idea di impero universale da Augusto a Teodosio ", dans Popoli $e$ spazio, op. cit. supra, p. 87 sq., qui cite de nombreux textes et inscriptions.

57. De lingua latina, 5, 143. Citent Varron également : Augusnin, Princ. dial., 11, 2 et Servius, Ad Aen., 1, 12.

58. Lex de imperio, 1,14 : " utique ei fines pomerii proferre promovere [...] liceat ", clause appuyée sur le précédent de la loi d'investiture de Claude (Auguste, dont les Res Gestae, 26, 1 , signalent une «augmentation des limites " de l'Empire, semble s'être abstenu de ce droit); cf. Verrius Flaccus, ap. Festus, p. $294 \mathrm{~L}$ : <ius > (selon la lecture vraisemblable d'Antonio Augustin, Venise, 1559) pomeri proferendi. SÉnÉque, De brev. vitae, 13, 8, relie l'usage ancien de ce droit aux annexions de territoires italiques et Aulu Gelle, N.A., 13, 14, 3, qui dépend de Valerius Messala, le subordonne à toute extension même provinciale: «celui qui avait augmenté le peuple Romain - pop. Rom. augere - en prenant des territoires à l'ennemi avait le droit d'étendre l'enceinte - ius proferendi pomerii " ; de mème TACITE, Annales, 12, 23, 2 : «Claude étendit l'enceinte, selon un ancien usage qui donnait à ceux qui avaient porté plus en avant l'empire, le droit d'agrandir aussi les limites de la Ville. " Cette extension de la ligne sacrée ne se confond pas avec celle des murs de défense qui la contiennent (Aulu Gelle, 13, 14, 44 : « ni le roi Servius Tullius, ni Sylla, qui demanda le droit d'étendre l'enceinte - proferundi pomerii titulum - ni ensuite le divin Iulius [César], lorsqu'il étendit l'enceinte, n'inclurent [l'Aventin] dans les limites prescrites pour la Ville "; cf. Trre-Live, 1, 44, 5 (le recul des murailles entraîne celui du pomerium, qui est donc contenu en elles) et $\boldsymbol{S H A}$ Aurélien, 21, 10, à propos des murs d'Aurélien, dont la construction précède la redéfinition de la limite pomériale. Sur les extensions pomériales, voir L. HerRMANN, « L. Antistius Vetus et le pomerium », Rev. Et. Lat., 1948, p. 224 sq. ; A. von BluMENTHAL, « Pomerium », RE, XXI, 2, 1 (1952), c. 1873 sq.; pour l'époque royale, A. MAGDELAIN, "Le pomerium archaïque et le mundus", dans Études, op. cit. supra n. 18, p. 155-191. 
mule d'origine sinon de facture ancienne, que complétera plus tard la règle : Rome est partout où séjourne l'empereur. Ainsi est instituée une véritable ubiquité de la Ville ${ }^{59}$.

Toutes ces qualifications et toutes ces normes suggèrent une maîtrise juridique du mouvement qui porte Rome - Ville et empire - à immobiliser ses augments en pérennité institutionnelle. L'imperium se stabilise en une entité politique, l'empire s'incorpore à l'Urbs par une procédure réglée, l'Urbs perdure toujours en tout lieu de l'empire, tout converge toujours vers la « commune patrie ». La « majesté de l'empire » prend sa signification parmi ces régulations abstraites de la puissance romaine. "Étendue du levant au couchant ", " diffusée dans l'univers ", elle est l'expression par excellence, durant les dernières décennies de la République et les premières du principat, de l'officialisation d'une grandeur en soi qui n'a d'autre terme de comparaison qu'elle-même. Et c'est elle que Tite-Live, dans la préface de ses Histoires, présente comme la principale clé pour comprendre le destin de Rome : «après un début fort modeste, la chose Romaine s'est accrue jusqu'à plier aujourd'hui sous le poids de sa propre grandeur ${ }^{60}$.

On peut résumer l'évolution esquissée jusqu'ici. Sous la République romaine, maiestas avait désigné d'abord l'éminence du pouvoir politique à l'intérieur d'un ordre pensé comme nécessairement hiérarchisé. Ce n'est pas avant le III siècle que s'affirme la majesté du peuple Romain : encore cette supériorité ne nous apparaît-elle pas alors comme celle des assemblées dans une hiérarchie interne, mais comme celle de Rome par rapport aux autres cités et à l'ensemble du monde. La suprématie des titulaires de l'imperium sur les citoyens formant le peuple s'était changée, au cours des siècles, en suprématie du peuple détenteur de l'imperium sur le monde. Mais qu'en était-il, pendant ce temps, d'une attribution de la majesté audedans? Le populus en était-il devenu le siège au-dessus des magistratures, comme veut le faire croire le récit canonique de son entrée en souveraineté, et celle-ci résidait-elle alors dans une partie, l'assemblée, placée au-dessus des autres? Ou bien la cité en était-elle investie collectivement

59. Digeste, $48,22,7,15-16$, etiam urbe abstinere debere; $18 \mathrm{pr}$., quia communis patria est. L'équivalence juridique entre l'empereur itinérant et la Ville de Rome est formulée par Callistrate au passage précité et par UlpIEN, Digeste, 3,2, 2, 4. Sur l'itinérance de la résidence impériale et sur les problèmes d'organisation administrative qu'elle pose, voir F. MiLLAR, The Emperor in the Roman World (31 BC - AD 337), New York, Cornell University Press, 1977, p. 28 sq.

60. Tite-Live, Praef., 4 ; également Horace , Odes, 4, 15, 15, à propos d'Auguste en 13 av. J.-C. : imperi porrecta maiestas ad ortus soli ab Hesperio cubiculo; PLINE, Hist. nat., 14, 2 ; autres textes cités par J. VoGT, dans Orbis. Ausgewählte Schriften zur Geschichte des Altertums, F. TAEGer et K. Krist éds, Fribourg/Bâle, 1960, p. 151 sq. ; également H. G. Gundel, art. cit. supra n. 3 , p. 306. 
sur chacun de ses membres, de la même manière qu'elle en était investie comme entité sur les cités soumises à son empire, en sorte que son accroissement dût se manifester en même temps par une extension en intensité, à l'intérieur, et par une extension en surface, au-dehors ?

En l'absence d'une documentation explicite, cette manière de nous interroger peut paraitre soulever des hypothèses vaines. Pourtant, c'est à peu près dans ces termes que la question se pose à partir des dernières années du $\mathrm{Il}^{\mathrm{e}}$ siècle avant notre ère. La majesté refait alors surface sur la scène de la controverse constitutionnelle, tout en poursuivant parallèlement, comme on l'a vu, sa carrière de lieu commun de l'impérialisme. La position des assemblées est définie à son tour en terme de maiestas, tout comme primitivement celle des magistrats supérieurs. Et ce ne sont pas seulement les partisans des démocrates, tels le tribun Memmius en 111 ou certains rhéteurs du début du $i^{\text {er }}$ siècle, autour des années 100 , qui définissent cette prépondérance nouvelle d'un terme réservé traditionnellement au statut de supériorité du pouvoir ${ }^{61}$ : ce changement devient un lieu commun et s'impose dans la langue du droit public. Cicéron le reconnait publiquement en s'adressant - par exemple en 63 et en 57 à la majesté du peuple assemblé ("maiestas vestra", formule qui sera bientôt transformée en " maiestas tua ", dans les adresses à l'empereur). Il oppose couramment celle-ci par ailleurs au commandement des magistrats ou à l'autorité du sénat ${ }^{62}$. Les tribuns de la plèbe en sont proclamés les garants, contre la réaction de Sylla qui leur avait retiré le droit de veto et l'initiative des lois ${ }^{63}$. Tite-Live et Florus, on s'en souvient, recueillent à propos de l'inclinaison des faisceaux la version canonique de sa première origine républicaine. Mais en même temps, le même concept qui désigne la souveraineté de l'organe populaire confronté à la magistrature et au sénat sert aussi d'instrument pour penser la transcendance du corps politique au regard de ses composantes. Est énoncée - et, on va le voir, protégée juridiquement - la maiestas du tout, sa supériorité sur chacune de ses parties. Le siège de la grandeur, désormais, c'est la civitas, la res

61. Harangue de Memmius en 111 : SAlluste, Jugurtha, 31, 17 (G. DumeziL, op. cit. supra n. 1, p. 133 et R. A. BaUman, op. cit. supra n. 16, p. 13, pensent qu'il est ici question de la m. de la plèbe, alors qu'il s'agit du populus, comme l'a bien vu J. L. Ferrary, op. cit. supra n. 5 , p. 564, n. 23). De inventione, 2, 52; partitiones oratoriae, 105.

62. Terme d'adresse aux assemblées : Ad Quirites, 4; Pro Rabirio perd., 25 ; cf. De lege agraria, 2,79 (où $m$. p. $R$. renvoie à l'assemblée dont la souveraineté est méprisée); également, le discours que SAlluste prête à Memmius en 111, Jug., 31, 9. Auctoritas du sénat et maiestas du peuple : Philippiques, 3, 13 ; également, Pro Sestio, 83 et Phil., 5, 25, où l'opposition est entre senatus et $m$. populi Romani; dans Pro Rabirio perd. reo, 2, texte dont Bodin faisait grand cas pour sa théorie de la souveraineté des assemblées populaires à Rome, la m. de la république est un tout à l'intérieur duquel s'inscrit l'autorité du sénat.

63. Scholia Gronoviana, p. 326, STANGl (decem tribuni eligebantur antea, qui quasi tuerentur populi Romani maiestatem... Hos omnes... sustulit Sulla) et SALLUSTE, loc. cit. supra n. 62 , où cette garantie est liée à la sécession sur l'Aventin. 
publica, le «nom romain " en tant que tels ${ }^{64}$ - lieux abstraits d'une grandeur qui n'est plus affirmée seulement par rapport au monde extérieur mais aussi par rapport à son intérieur, en quelque sorte pour ellemême et hors comparaison.

L'idée tournée au-dedans est mise au service d'un lien politique exprimé comme hégémonie, ce qui heurte et prend à rebours le sens de la relation qui, à Rome, fait traditionnellement de la civitas la résultante des citoyens - plutôt que des citoyens les éléments de la cité -, du peuple une association qui n'a pas d'antériorité logique sur les hommes qui le composent, et de la république une communauté sans personnalité séparée de ceux qui la composent ensemble - sans personnalité morale propre, autrement dit $^{65}$. Convertie vers l'intérieur de la relation politique, la majesté transforme cette relation d'après le modèle de la domination du pouvoir, d'après le modèle aussi d'un empire qui ne serait plus celui de la cité sur le monde, mais celui de la cité sur les citoyens. Entendue comme un absolu qui n'est plus rapporté qu'à soi, la grandeur affecte dès lors le régime de l'appartenance à l'entité romaine. Appartenance qui comporte l'idée très claire d'une prééminence, pensée comme hiérarchie, du soi collectif en soi.

64. " M. de la cité » : Rhétorique à Herennius, 2, 12, 17 (procès de Servilius Caepio en 95 ) ; 4, 25, 35 (procès fictif de Popilius en 107) ; Cictron, De oratore, 2, 164 (procès de Norbanus en 95); Divinatio in Caecilium, 69 (sous Scipion l'Africain, « le nom Romain était florissant, l'autorité de l'empire et la majesté de la cité avaient un grand poids ").

"M. de la République ": Rhet. Heren., 4, 35; Cicéron, Verrines, 2, 5, 50 (lex Comelia de 81), cf. laesa respublica dans les Controverses de SÉnteue le Rhéteur - 9, 2;10,4;10, 5 et maiestatem publicam laedere dans la lex Iulia, Digeste, 48, 4, 3; ValÉre MAXime, 4, 1, 8 ; $6,4,2 ; 9,2,3$.

"M. du nom Romain ": CicEron, Partitiones oratoriae, 30, 105; TrE-Live, 2, 48, 8 ; Arnobe, Adversus nationes, 7, 49 (à ne pas confondre avec la « $\mathrm{m}$. du nom de Rome », dans Panégyrique, 6 (7), 10, 5, équivalent de la "majesté de la Ville » qui, depuis le principat d'Auguste et durant tout l'Empire, représente symboliquement et esthétiquement la Majesté en soi : Vitruve, 2, 8, 7; Tacre, Histoires, 1, 90;3, 12, 2; Panégyrique, 2 (10), 14, 13 et 9 (12), 16, 2; Code Théodosien, 11, 20,3).

“M. romaine »: Trie-Live, 3, 69, 3; Florus, 4, 2, 8; Valère Maxime, 8, 15, ext. 1 ; Pline, Hist. nat., 15, 19 ; Dioclenen, Collatio leg., 6, 4, 6.

Toutes ces formules mettent l'accent sur l'entité étatique (ce point a été justement souligné par J. L. Ferrary, op. cit. supra n. 5, p. 569-570). Dans la mesure où senatus populusque Romanus désigne le sujet politique dans sa totalité, cet ensemble complexe peut à bon droit être dit aussi détenteur de la majesté (Cickron, Pro Sestio, 12, cf. H. G. Gundel, art. cit. supra n. 3, p. 308).

65. On pense ici aux importantes remarques d'E. BENVENISTE sur civitas, abstrait dérivé de civis - au contraire de polis, qui est premier par rapport à politès : " Deux modèles linguistiques de la cité ", Mélanges Lévi-Strauss, I, Paris, 1972, p. 589-596. Du côté grec, sur la priorité de l'entité civique par rapport à ses composantes, telle qu'elle est exprimée à travers l'idéologie de l'oraison funèbre, voir N. Loraux, L'Invention d'Athènes, Paris, 1981. Sur l'immanence de la notion de populus dans les institutions, voir P. Catalano, Populus Romanus Quirites, Turin, 1974. Sur la difficulté à construire juridiquement res publica comme une personne morale, voir les remarques de R. ORESTANO, $I l$ problema delle "persone giuridiche" in diritto romano, Turin, 1968 , p. 111 sq. et 280 sq. 
Cette éminence est juridiquement protégée, à partir du $\mathrm{I}^{\mathrm{er}}$ siècle avant notre ère, par des lois qui l'érigent en sanctuaire inviolable. Des lois sanctionnent alors la défense de la « diminuer ». Attenter à la Grandeur en la réduisant est devenu un crime, et c'est sur cet interdit que désormais se décide le contour de la majesté. Or cette légalisation par la loi criminelle en change radicalement la nature. II ne s'agit plus maintenant d'une simple idée constitutionnelle, d'un concept servant à rendre intelligible un caractère du droit public romain, une structure de sa disposition interne et externe. Nous quittons le plan discursif des idées politiques pour aborder celui du droit, discipliné par le langage, certes, mais défini surtout par des actes. La majesté devient une institution au sens propre et concret du terme, en ce qu'elle doit sa réalité aux faits (et pas seulement aux mots) que la légalité détermine : elle surgit dans les transgressions qui la lèsent, s'impose dans les procédures qui la préservent, triomphe dans les condamnations par lesquelles elle est rétablie. Bien sûr, un nominaliste - autrement dit un sociologue - dirait que l'unité de tous ces faits et de toutes ces pratiques est verbale, et que l'apparente substance de la maiestas dissimule une infinité d'événements et de rapports de pouvoir que l'on pourrait regrouper plus véridiquement. Mais cette méthode est inapte à expliquer autrement que sur le mode de l'artifice et de la fausse conscience les constructions institutionnelles, en pratiquant à leur endroit le soupçon radical pour mettre au jour un autre réel plus réel, qui n'émergerait qu'après l'effacement de ce qui est explicitement dit. Elle échoue surtout à comprendre l'effectivité de ces découpages, trop souvent confondus avec des productions idéologiques ou bien avec un " discours ", terme assez vague pour suggérer, sans avoir à la préciser, quelque position moyenne entre l'explicite et le réel, entre les mots et les choses. L'intelligence de la légalité institutionnelle exige au contraire qu'on la prenne à la lettre, puisque dans la réalité de son fonctionnement, c'est à la lettre que sont rapportés ses multiples effets. Cette référence même est son ressort principal. En dehors d'elle, le phénomène juridique se dissout. Non pour laisser la place à une autre analyse des faits, mais pour disparaître tout simplement comme fait. Dire qu'avec l'institution du crimen la majesté prend une consistance nouvelle n'est donc pas afficher un parti pris idéaliste, mais simplement rendre compte du fait que des accusations, des procédures, des peines, bientôt la délation, l'enquête secrète et la torture, toute une matière vivante où l'historien aimerait voir tailler, n'adviennent qu'en son nom. Prenons brièvement connaissance, tout d'abord, des lois successives. 
En 100, une loi du tribun de la plèbe Appuleius Saturninus institue le premier tribunal spécialisé dans la poursuite des actes tombant sous l'imputation de "minuere maiestatem ", sans préciser les faits constitutifs du délit. Mais les procédures fondées sur la lex Appuleia mirent en cause d'anciens magistrats qui avaient utilisé la violence et mobilisé des attroupements de leurs partisans pour obtenir ou pour empêcher le vote d'une loi : manière d'agir qui s'apparentait à la sédition, vieille notion du droit disciplinaire militaire étendue au domaine des luttes civiles à partir des Gracques. Dans l'un au moins des procès que nous connaissons, en 95, la seditio figure explicitement dans l'acte d'accusation, comme fait constitutif de la lèse-majesté ${ }^{66}$. En 90, le tribun Varius Hybrida établit sous le chef de majesté un jury spécialement chargé de condamner ceux qui avaient incité les alliés italiques à prendre les armes contre la domination romaine : acte proche de l'ancien délit, défini par la loi des douze Tables (450 av. J.-C.), consistant à soulever les ennemis de l'extérieur (hostem concitare), et qui est l'une des modalités de la trahison, proditio ${ }^{67}$. En 81,

66. Sur la loi de Saturninus, voir A. W. Zumpt, Das Criminalrecht der römischen Republik, Berlin, 1868, II, 1, p. 227 sq. ; A. BERGER, « Lex Appuleia de maiestate », R.E., 12, 2, s.v. et surtout J. L. FerRarY, dans CRAI, op. cit. supra n. 5 , p. 565 sq. Sur l'ancienne notion de sédition, C.H. Brechr, Perduellio, Munich, 1939 (pour la sédition militaire, p. 65 sq., à quoi il faut ajouter l'attestation par les Fastes Capitolins d'un dictator seditionis sedandae causa en 368; sur l'extension de cette catégorie aux luttes civiles à partir des Gracques, voir quelques références p. 50, n. 4. II manque une étude précise sur ce sujet d'histoire républicaine). Les procès de certains partisans de Saturninus peuvent s'être déroulés devant le tribunal de majesté au titre de la sédition, puisque tel fut le titre qui les fit déclarer ennemis publics par le sénat : Cicéron, Pro Rabirio perd. reo, 3 ; 24 ; cf. VAlére Maxime, 3, 2, 18 et 9, 7, 1. Seditio est en tout cas le chef de majesté sous lequel fut accusé Norbanus en 95 , pour avoir imposé contre la volonté du sénat et par violence le vote d'une loi dix ans plus tôt (CICÉron, De or., $2,49,200$ ), où l'argument du défenseur, selon lequel l'accusé avait fait prévaloir la souveraineté populaire " même s'il avait fallu employer pour cela la sédition ", etiam cum seditionis cuniunctione, est une réfutation mot pour mot de l'acte d'accusation, selon les règles rhétoriques de la ratio de la défense, à laquelle répond en dernier lieu la rationis infirmatio de l'accusation. Cette dernière se lit dans les Partitiones oratoriae, $105:$ « la majesté réside dans la dignité de l'empire et du nom romains, que diminue quiconque a conduit par la violence et en appelant à la sédition les intérêts de la multitude ", per vim multitudinis rem ad seditionem vocavit. La question posée au juge, ou disceptatio, est une synthèse des positions de la défense et de l'accusation, et s'énonce ainsi : « est-ce diminuer la majesté, que d'imposer par la violence une décision qui a l'agrément du peuple Romain et qui apparait équitable ? " Sur la seditio Norbana, voir J. L. Ferrary, MEFRA, 1979, p. 92 sq. et CRAI, op. cit. supra n. 5, p. 560 sq. En 95 encore, les accusateurs de Quintus Servilius Caepio lui reprochent de s'être opposé au projet de la loi frumentaire de Saturninus cinq ans plus tôt, en empêchant l'accès aux urnes (Rhet. Heren, 1, 12, 21 et 2, 12, 17; sur cette affaire, R. A. BAUMAN, op. cit. supra n. 16, p. 46 sq.; A. W. ZuMPT, op. cit. supra n. 66, II, 1, p. 227 sq.; J. L. FerrarY, op. cit., p. $565 \mathrm{sq}$., dont il faut suivre la chronologie) : mais nous ignorons si cette violence politique, poursuivie au nom de la maiestas, fut qualifiée de seditio, par un retournement qui aurait mis ce délit à la charge des oligarques, alors qu'il l'était traditionnellement à celle des démocrates.

67. XII Tables (Digeste, 48, 4, 4); Asconıus, In Scaurianam, p. 22, Clark (belli concitati crimen) et Ciceron, ad loc (proditionis crimen). Sur proditio, voir C. H. BrECHT, Perduellio, op. cit. supra n. 66, p. 27 sq. 
enfin, Sylla codifie d'une manière systématique la matière pénale de la lèse-majesté.

Sous la loi de Sylla entrent un grand nombre de délits commis dans l'exercice du pouvoir ou de délits contre le pouvoir, qui traditionnellement relevaient de qualifications pénales distinctes et n'obéissaient pas tous aux mêmes procédures : un unique crimen, le crimen maiestatis, recouvre désormais la presque totalité du champ de la criminalité politique. Nous ne possédons que d'infimes données sur la lex Cornelia, mais les quelques témoignages qui nous en restent permettent de regrouper ainsi les faits qu'elle énumère :

1) incitation des légions à la révolte et à la sédition militaire, punies autrefois comme seditio ;

2) reddition militaire, abandon d'une place forte, d'un camp, d'armes et de munitions à l'ennemi ;

3) insoumission des généraux par rapport à l'autorité politique et transgression des limites de leur charge, consistant par exemple à quitter pendant leur temps de fonction leur secteur d'opération - leur " provincia » - , à en faire sortir l'armée, à déclarer la guerre de leur propre initiative, à envahir un royaume étranger sans un ordre exprès du peuple ou du sénat, à refuser de laisser leur province à l'arrivée de leur successeur;

4) fautes graves dans l'administration d'une promagistrature, dont il résulte un affaiblissement de la puissance romaine, une diminution de ses moyens militaires et fiscaux (omettre d'exiger le tribut d'une province en hommes et en fournitures militaires, etc.);

5) comportement séditieux des magistrats et incitation aux manifestations de violence;

6) attentats contre le pouvoir, comme porter atteinte à la vie d'un consul, menacer un détenteur de la puissance publique;

7) pouvoirs usurpés par d'anciens magistrats redevenus personnes privées ${ }^{68}$.

68. 1) Procès de majesté contre Staienus, Cicḱron, Pro Cluentio, 99 : eius opera, cum quaestor esset, in exercitu seditionem esse conflatam; contre Marcus Atilius Bulbus, Cluent, 97 : legionem esse ab eo sollicitatam. 2) Procès de Popilius en 107, réinterprété plus tard, dans les écoles de rhétorique, comme un cas relevant de la loi de majesté : celle-ci devait donc comporter un article qui s'y prêtait (Ad Herennium, 1, 25; 4, 34; De inventione, 2, 72 73). 3) CiCERON, In Pisonem, 21, 50 : Mitto exire de provincia, educere exercitum, bellum sua sponte gerere, in regnum iniussu populi Romani aut senatus accedere, quae... lex Cornelia maiestatis... vetat et procès de Gabinius en 54 (voir E. Clacieri, Processi politici e relazioni internazionali, Rome, 1918, p. 227 sq.) et d'Appius Claudius Pulcher en 50 (Cićron, Fam., III, 11, 2, cf. III, 6, 3; voir R. A. BAuman, op. cit. supra n. 16, p. 79). Le refus de quitter sa province est réuni aux précédents cas de désobéissance par la lex Iulia (Digeste, 48, 4, 2). 4) II Verr., 5, 50 : Verrès a négligé d'exiger des Mamertains un vaisseau de guerre auquel les obligeait un traité (minuisti maiestatem reipublicae, minuisti auxilia populi Romani, minuisti copias maiorum virtute ac sapientia comparatas, sustulisti ius imperii, conditionem sociorum, memoriam foederis ; cf. PorCIUs LATRo, ap. SÉNÉQue, Contr., 10, 4, 11 : vectigalia deminuta); il a épargné la vie des capitaines des pirates (II Verr., 1, 5, 12). En revanche, la qualification de $m$. donnée au pillage d'œuvres d'art témoins de la domination romaine (II Verr., 4, 41, 
Cette liste n'est assurément pas exhaustive : elle ne considère que les délits répertoriés sous le chef de majesté par une documentation tardorépublicaine incomplète, dont nous n'avons pas le droit de combler les lacunes en empruntant à la législation beaucoup mieux connue d'Auguste - même si la lex Iulia reprend à son compte la plupart des faits déjà sanctionnés par la lex Cornelia. Cette liste n'est surtout pas établie selon le plan original de la loi, qui nous échappe entièrement. L'éparpillement des allusions condamne toute tentative d'articulation qui se prétendrait authentique. Au mieux peut-on regrouper quelques données composant un sous-ensemble, lorsqu'un même texte les associe ${ }^{69}$, et sans perdre de vue que, dans les citations d'un seul tenant que les jurisconsultes impériaux font de la lex maiestatis d'Auguste, sont juxtaposés parfois des actes apparemment hétérogènes ou se retrouvent séparés au contraire, comme s'ils n'avaient aucun rapport entre eux, des actes que nous tiendrions pour apparentés. Cependant, quels qu'aient pu être le contenu et l'ordre primitifs de la loi de Sylla, nous sommes en mesure de voir qu'elle regroupait un vaste ensemble de délits, recueillis en un code du crime d'État. Les uns avaient une très lointaine origine militaire et relevaient traditionnellement de la juridiction consulaire pour trahison au profit de l'ennemi (proditio); d'autres étaient poursuivis depuis le iI' siècle par les tribuns de la plèbe au titre de la trahison interne et de l'atteinte à la sécurité de l'État (perduellio), accusation dont étaient menacés surtout les magistrats en raison d'un manquement aux devoirs de leur charge; d'autres enfin, plus récents, sanctionnaient une véritable charte de la promagistrature, c'est-à-dire du commandement provincial. Nous ignorons si les actes de sédition civile étaient inclus dans cet ensemble, comme ils l'avaient été dans les applications de la lex Appuleia de 100, et comme ils devaient l'être plus tard de nouveau dans la loi d'Auguste ${ }^{70}$. Si tel fut le

88 : est maiestatis, quod imperi nostri gloriae, rerum gestarum monumenta avertere atque asportare ausus est) p. $59 \mathrm{sq}$. est une amplification rhétorique et vient faire redondance avec la concussion, le péculat et le sacrilège. 5) C. Manilius est accusé de maiestate en 66 pour avoir fait voter une loi grâce à une émeute d'esclaves et d'affranchis (Scholies de Bobbio, p. 119, Stangl.; Asconius, p. 45, Clark); cependant, comme Sylla avait supprimé les droits politiques du tribunat de la plèbe, il est douteux que la loi de majesté ait régi le cas des tribuns (voir infra, p. 375-376, avec le cas de Cornelius). 6) Atteinte à la vie du consul : CiceRON, Interrogatio in Vatinum, 22 (Bibulus est réduit à la protection des murs de sa maison, cum... non maiestate imperii, non iure legum, sed ianuae praesidio et parietum custodiis consulis vita tegeretur). 7) CiCÉRON, II Verr., 1, 12 (cf. 76) : Verrès a continué de garder chez lui, après être redevenu privatus, les chefs des brigands dont il avait eu la garde comme gouverneur de province : Hoc in illo maiestatis iudicio... ego oportuisse concedam. Mais il s'agit peut-être d'une amplification rhétorique. Sur la lex Comelia, voir R. A. BaUman, op. cit. supra n. 16 , p. 59 sq., qui insiste à juste titre sur les délits proconsulaires.

69. Cela n'arrive qu'une fois : Cićron, In Pisonem, 21, 50 (voir supra n. 68, n⿳3).

70. Rien ne prouve que la seditio était formellement inscrite dans la lex Cormelia et notamment pas Cickron, Part. or., 105, comme le croit J. D. Cloud, « The Text of Digest 48, 
cas, alors le champ de la maiestas diminuta syllanienne dut correspondre à peu près aux trois domaines délictuels auxquels, selon Tacite, s'étendait pour les Anciens - c'est-à-dire à l'époque républicaine, avant le principat d'Auguste - le crime de majesté : la trahison militaire, la sédition populaire et l'administration fautive de la chose publique ${ }^{71}$. $\grave{A}$ ces délits imputables principalement à des magistrats s'ajoutaient, enfin, les attentats contre les titulaires du pouvoir, meurtres, outrages ou violences.

C'est une véritable codification de droit criminel politique, compilant une pratique pénale plus ancienne et réglementant systématiquement l'exercice des hautes fonctions publiques, notamment dans les provinces, que la loi syllanienne unifiait sous le nom de majesté. Une loi de César, en 47 ou en 46, introduisit dans cet ensemble la répression des violences urbaines et les séditions civiles imputées à d'autres qu'à des magistrats ${ }^{72}$. Le tout fut définitivement réaménagé par Auguste, à une date que nous ignorons, mais par une loi - la lex Iulia que citent les compilations justiniennes - qu'il faut lui attribuer, en dépit de nombreuses tentatives pour la confondre avec la législation précédente de César ${ }^{73}$. Sur cette lex Iulia, dernière d'une longue série, s'appuie l'organisation des poursuites poli-

4: ad legem Iuliam maiestatis ", ZSS, 1963, p. 209 : car œ passage renvoie au procès de Caepio en 95, sous le régime de la lex Appuleia (voir supra n. 66). Le seul indice est peut-être le procès de Manilius en 66, encore qu'il ne s'agisse pas à proprement parler de seditio et que le cas des tribuns de la plèbe n'ait probablement pas été prévu par la loi (voir n. 68, $\mathrm{n}^{\circ} \mathrm{S}$ et infra, p. 375 sq.)

71. TACre, Annales, 1, 72.

72. Ciceron, Philippiques, 1, 21, 22, 23. R. A. Bauman, op. cit. supra n. 16, p. 155 sq. ; A. W. Lintort, Violence in Republican Rome, Oxford, 1968, p. 107 sq.

73. Pour une identification césarienne de la lex lulia se sont prononcés en particulier J. F. Alluson et J. D. Cloud, "The lex Iulia Maiestatis ", Latomus, 1962, p. 711-731, en développant l'argument selon lequel aucun texte n'en préciserait l'attribution, contrairement à la lex lulia de César, qui est attestee par Cicéron en 44. Mais il est impossible d'interpréter comme le font ces auteurs, TACrTE, III, 24. Car si Auguste, selon Tacite, « transgressa luimême ses propres lois " - suasque ipse leges egrediebatur - en poursuivant pour lèsemajesté et en mettant à mort les amants complices des adultères de sa fille, ce n'est pas, comme le croient ces auteurs, parce qu'il avait aggravé la peine de sa loi sur l'adultère (le dépassement d'une peine n'était pas compté, sous l'Empire, pour une violation de la loi, et Tacite en particulier ne mentionne jamais de tels dépassements comme illégaux); la transgression tient ici évidemment au fait qu'Auguste avait étendu sa loi de majesté à l'adultère, en "qualifiant une faute si répandue entre hommes et femmes du nom terrible de violation de la majesté ", œ qui ne s'était jamais vu. TACrrE, A. 4, 34, fournit un autre indice : la loi de majesté appliquée par extension aux injures verbales et aux écrits séditieux " embrasse le prince et son père ", c'est-à-dire Auguste et César (œe que confirme Dion CAssius, 57, 24, 3), et non pas Tibère et Auguste, ainsi que le croient J. F. Alusson et J. D. Cloun, art. cit. supra, p. 720 ; même erreur chez R. A. BAUMAN, op. cit. supra n. 16, p. 270; Auguste dut ainsi prendre lui-même la décision de faire remonter la défense de sa majesté jusqu'à la mémoire de son propre père divinisé (Dion Cassius, 57, 15, 6, l'atteste à propos de la condamnation de Scribonius Libo en 16, sous Tibère), $\infty$ qui tend à laisser croire qu'il avait interprété ou fait interpréter sa propre législation sur la maiestas. La datation de sa loi reste cependant un problème insoluble. R. A. Bauman, op. cit. supra n. 16, p. 274 sq., propose 27 av. J.-C.; V. Arangio Runz (dans Studi in occasione del bimillenario di Augusto, Rome, 1938, p. 202 sq.) et K. M. T. Atxinson (Historia, 1960, p. 446 sq.) proposent 18 av. J.-C. ; L. Schu- 
tiques durant tout l'Empire romain - et même au-delà, puisqu'elle fut transmise aux juristes et aux légistes du Moyen Âge à travers le Digeste et surtout à travers les constitutions adventices qui se greffent sur elle dans le Code. Mais son contenu littéral est pour une grande part translatice et reprend une matière organisée à l'époque tardo-républicaine.

Voici, résumés dans leurs principaux traits, la teneur des délits qu'elle intègre dans ses poursuites (entre crochets sont signalées les dispositions qui figurent d'un seul tenant dans les citations compilées au Digeste, et qui ont donc toute chance d'avoir obéi à une certaine logique associative dans l'esprit du législateur antique ; les autres sont isolées et introduites ici, avec tous les risques de l'arbitraire, dans le contexte qui leur convient le mieux).

I) < a) entreprendre une guerre, recruter des hommes, lever une armée sans un ordre du peuple Romain

b) refuser de remettre l'armée à son successeur arrivé dans la province (un autre fragment parle du refus de quitter la province)

c) abandonner en cours de charge son commandement militaire

d) exercer un pouvoir public sans revêtir une magistrature $>$

e) mettre à mort des otages sans un ordre du peuple Romain

f) falsifier un document public

g) libérer en cours d'enquête un détenu qui a avoué son crime, c'est-à-dire s'arroger le droit de grâce.

Ces infractions aux devoirs des magistrats et des promagistrats, tant à Rome que dans les provinces, avaient été définies en partie déjà par la loi de Sylla et c'est elles que Tacite résume sous le nom de " gestion fautive de la chose publique ", male gesta res publica ${ }^{74}$.

macher, Servus index, Wiesbaden, 1982, p. 113 sq., propose 8 av. J.-C. ; E. KoestermanN, Historia, 1955 , p. 77, propose les dernières années du règne d'Auguste.

74. Successivement, a)-d) : MARCianus, D., 48, 4, 3, d'un seul tenant; dans a), " iniussu principis " est certainement interpolé à la place de iniussu populi Romani : J. Cloud, art. cit. supra n. 70 ; p. 218 sq. ; cf. Sententiae Pauli, V, 29, ad Iuliam maiestatis, 1 : quive iniussu imperatoris bellum gesserit, dilectumve habuerit, exercitumve comparaverit; e) : début de $\mathrm{D}$., 48, 4, 1, qui ouvre illogiquement le passage du De officio proconsulis d'UlPIEN, consacré aux séditions et aux violences, et où iniussu principis est également interpolé (J. CLoud, art. cit. supra n. 16, p. 212) ; $\mathrm{f}: D ., 48,4,2 ; \mathrm{g}): 48,4,3$. Puisque la falsification des documents publics figurait dans le premier chapitre de la loi $(48,4,2$, in fine) et puisque TACrte $(A ., 1$, 72) regroupait en une seule catégorie les faits de male gesta res publica, on peut raisonnablement supposer que tous ces faits trouvaient leur place dans une première partie. KOBLER, $R E$, $\mathrm{XIV}, 1$, c. 550, regroupe les données à peu près de même, mais sans suivre l'ordre exact des citations, et en rejetant e) dans une autre partie, celle de la haute trahison militaire (ici, III). R. A. BAUMaN, op. cit. supra n. 16, p. 283, ne tient aucun compte de l'ordre des citations ni de l'indication " in hoc primo capite", ce qui lui fait placer les délits d), f), g) immédiatement à la suite des séditions urbaines (ici, III) et séparément des délits d'administration provinciale auxquels d) s'enchaîne. 
II) < a) Renseignements fournis par messages et par signes aux ennemis extérieurs du peuple Romain, pour les aider dans leurs entreprises hostiles

b) soulèvements de soldats (sollicitare, concitare) en vue d'une sédition militaire (seditio et tumultus) >

c) désertion et passage à l'ennemi (desertio et transfugium)

d) abandon de poste à la guerre, remise à l'ennemi d'une place forte ou d'un camp

e) < pièges tendus à l'armée romaine pour la livrer à l'ennemi (proditio)

f) obstacles mis à la reddition de l'adversaire

g) fourniture à l'ennemi en vivres, armes, chevaux, argent

h) incitation faite aux alliés du peuple Romalin à passer dans le camp adverse

i) incitation faite aux rois de nations étrangères à désobéir au peuple Romain

j) mancuvres ayant eu pour résultat la fourniture des ennemis du peuple Romain en otages, argent, chevaux. $>$

Tous ces délits se commettent à l'armée et en temps de guerre. Ils relèvent de la trahison militaire (All. Landesverrat). C'est eux que, conformément à la tradition, Tacite regroupe sous le nom de proditio ${ }^{75}$.

III) < a) attroupements dans la ville avec port d'armes et occupation des lieux publics et sacrés

b) réunions factieuses et appels à la sédition (coetus conventusque ad seditionem)

c) meurtre d'un magistrat du peuple Romain ou d'un titulaire de la puissance publique

d) guerre civile armée - tout cela «contre la res publica » >

e) conjurations contre la res publica («faire prêter serment d'œuvrer contre la res publica $n)$.

La lex Iulia associe donc apparemment dans une même section des crimes réunis par Tacite sous le nom de seditio, crimes que nous qualifierions aujourd'hui d'atteinte à la sécurité intérieure de l'État (All. Hochverrat ${ }^{76}$. Tels sont, selon le texte de la dernière loi de maiestate - il n'y

75. Successivement, a)-b) : ULPIEN, 7 De officio proconsulis $D ., 48,4,1$ in fine (b :SP., V, 29,1 : sollicitaveritque exercitum); c) : UlPIEN 8 disputationum, D., 48, 4, 2 ; d) : MARCIANus, D., 48, 4, 3 ; e)-j) : SCaEvola, D., 48, 4, 4 d'un seul tenant (e : S.P., V, 29, 1 : exercitusve eius in insidias deductus est). Cet ensemble est regroupé sous le chef de proditio par TACrTE, Annales, 1, 72 : si quis proditione exercitum... maiestatem populi romani minuisset, cf. 6, 8 : insidiae in rem publicam. B. KUBLER, c. 549 et R. A. BAUMAN, op. cit. supra n. 16, p. 280, brisent l'unité de ces délits militaires, en regroupant les séditions à l'armée avec les séditions civiles (ici, III).

76. Successivement, a)-d) : UlPiEN, 7 De officio proconsulis, $D ., 48,4,1$. Pour a) et b), il faut noter que les Sententiae Pauli réservent à la seditio un titre autonome détaché de la lex Iulia : V, 12, De seditiosis, où sont juxtaposés aux séditions et aux soulèvements proprement 
en aura plus d'autre avant une loi d'Arcadius et Honorius en 397 - , les différents actes compris sous ce chef d'inculpation.

L'idée de grandeur hégémonique, passée de la sphère du pouvoir interne à celle des relations d'empire avec le monde, s'était reconvertie vers l'intérieur de la cité, mais avec une force nouvelle que lui procurait l'interdit. La maiestas populi Romani s'érigeait en référence juridique infrangible, en zone d'inviolabilité sanctifiée par la loi. Il est possible que la toute première loi, celle du tribun Saturninus, en 100, en cette année de violents conflits entre oligarques et démocrates, n'ait d'abord visé qu'à préserver le droit éminent des assemblées par rapport au sénat qui s'employait à lui faire obstacle : selon la démonstration solidement argumentée de J.-L. Ferrary, la toute première loi de maiestate fut probablement une machine de guerre de la politique tribunicienne au service de la souveraineté comitiale du peuple, sur fond de politique du blé à bas prix et de législation frumentaire. À cette prétention, le sénat réagit d'ailleurs en restaurant par le coup de force d'un sénatus-consulte ultime la " majesté de la cité ", que cette législation réduisait, et fit massacrer Saturninus et ses partisans sur la base de ce droit de supériorité que l'entité romaine détenait par-dessus la souveraineté même du peuple ${ }^{77}$. L'événement voit s'affronter ainsi les deux conceptions de la majesté qui, on s'en souvient, coexistaient à Rome au $\mathrm{I}^{\text {er }}$ siècle et sans doute bien auparavant : d'un côté, la suprématie des assemblées populaires par rapport à la magistrature et au sénat, qui renversait l'ordre primitif de la subordination du peuple par rapport au pouvoir; de l'autre, la suprématie d'un être moral appelé tour à tour "cité ", "chose publique", " peuple Romain ", « nom Romain », « Rome », si ce n'est, dans un sens encore plus abstrait, la majesté elle-même et en tant que telle, c'est-à-dire

dits les destructions des limites des propriétés foncières et la circoncision des Romains et de leurs esclaves selon le rite Juif. Pour d), cf. PS, V, 29, Ad Iuliam maiestatis, 1 : « celui par l'action ou par le projet duquel adversus imperatorem vel rempublicam arma mota sunt". e) : SCAEVOLA, D., 48, 4, 4, avant une longue série de faits de haute trahison militaire, ci-dessus II, e-j. Cet ensemble est regroupé sous le chef de seditio par Tacre, Annales, 1, $72:$ si quis... aut plebem seditionibus... Sur le problème de l'authenticité des citations du Digeste, on ne peut accepter l'idée d'A. N. ShEkWIN WHIT, cité supra n. 1, p. 290, selon laquelle Ulpien et Marcianus pourraient n'avoir cité que des interprétations plus tardives par voie de sénatusconsultes, comme le fait Venuleius dans le frag. 6 relatif aux attentats contre l'image du prince : les donnèes qu'ils ont compilées n'intéressent en effet que la magistrature, le populus et la res publica, ce qui constitue au $\mathrm{II}^{e}$ siècle une preuve d'authenticité. Sur l'adéquation des fragts 1 à 4 au droit de la fin du dernier siècle avant notre ère, voir J. D. CLouD, art. cit. supra n. 70, p. 207. Sur le résumé des Sententiae Pauli, voir G. G. ARCHI, « I Nuovi frammenti e il diritto criminale romano (Cod. Leiden BPL 2589) ", dans Scritti, III, Milan, 1981, p. 14511485 (not. 1455 sq.) et F. Serrao, $l l$ frammento leidense di Paolo. Problemi di diritto criminale romano, Milan, 1956.

77. J. L. FerRary, dans CRAI, op. cit. supra n. 5 , p. 566 sq. 
une grandeur devenue à elle-même son propre substrat ${ }^{78}$. Mais si l'histoire politique éclaire l'événement que constitue cette loi en 100 av. J.-C., dans le contexte où elle fut votée, l'événement disparaît aussitôt derrière l'institution auquel il avait donné lieu. Cela est vrai, sans doute, de toute institution en général. Mais cela est particulièrement vrai de la maiestas romaine, dont l'indétermination première était maintenant affermie par la sanction d'un crime. Cette consolidation par le crimen assurait et en quelque façon établissait l'infinitude du sens, quelle qu'en fût la portée exacte au moment de sa reconnaissance légale. Atteinte à la suprématie du peuple en assemblée sur les autres pouvoirs ou atteinte à la suprématie d'une idéalité élevée jusqu'à n'avoir d'autre essence que sa hauteur même, l'amputation de la majesté ouvrait sur une virtualité d'inculpations infinie, élargissant l'empire de la grandeur aussi loin au-dedans de Rome, en direction d'un approfondissement du lien d'allégeance politique, qu'elle s'élargissait au-dehors, dans l'empire, en principe indéfiniment.

Les lois suivantes, celles de Sylla, de César puis d'Auguste, font entrer sous cette inculpation unique la plupart des délits politiques poursuivis à des titres divers sous la République romaine, plus un certain nombre d'autres, et organisent le tout en système. Ces chartes de la haute trahison et du crime d'État rapportent en principe à la cité, à la res publica, à la totalité politique du populus Romanus, la « grandeur » qu'elles instituent pénalement. De ce point de vue, la lex Iulia elle-même respecte une parfaite orthodoxie républicaine. Son texte ne reconnaît d'autre sujet de la majesté que la collectivité, que l'ensemble des Romains en personne : nulle place n'est encore laissée à la maiestas du prince, qui pourtant s'impose sans partage dans les années qui suivent immédiatement cette loi. Il n'est toujours question, dans la lex Iulia, que du populus Romanus et de la res publica ${ }^{79}$.

Mais, plus que le support abstrait de la majesté, importe l'idée quantitative qui continue de régir son régime pénal, après avoir présidé à sa vocation expansionniste impériale. Il convient ici d'attacher la plus grande importance à l'expression singulière de l'interdit, modelée sur les variations d'amplitude du domaine préservé par lui. La modalité de l'acte est moins, selon le verbe légal, l'infraction qui brise et qui rompt, que

78. Le s. c. de 100 est défini comme «suprême recours de la majesté et du pouvoir », summum auxilium maiestatis atque imperii par CrCERon, Pro Rabirio perduellionis reo, 2.

79. Ainsi, "populus romanus": D., 48, 4, 4; "adversus populum romamum ": 4, 1 ; "magistratus populi romani " : 4, 1 ; "hostes populi romani " : 4, 1 et 4, 4; imperium exercitumve populi romani »: 4, 3; "exercitus populi romani »:4, 4; « adversus rempublicam ": 4,1 et $4,4,4$; "maiestas publica " : 4, 3. On ne trouve de références à Caesar, au princeps et à la principalis maiestas que dans les interprétations $(4,5:$ images de Caesar; $4,7:$ injures verbales; 4, 11 : adversus rempublicam vel principem, cf. S.P., 5, 29, $1:$ adv. imperatorem vel rempublicam), ainsi que, dans le corps même des citations, dans deux passages interpolés (voir supra n. 75). 
l'amoindrissement de ce qui par hypothèse ne peut décroître : la lex Appuleia, la lex Cornelia, la lex Iulia de César ne connaissent d'autre qualification que "maiestatem minuere ${ }^{80}$; et ce fut sans doute aussi le cas de la loi d'Auguste ${ }^{81}$. À une telle imputation, d'ailleurs, l'accusé ne pouvait opposer meilleure défense qu'en soutenant qu'il avait par son action, au contraire, " augmenté la majesté ${ }^{82}$. Le non-délit, le moindre mal eût été de l'avoir « maintenue en l'état ", retinere maiestatem, d'avoir observé à son endroit un impératif de conservation analogue à l'obligation où les cités sujettes étaient, on s'en souvient, de la préserver ${ }^{83}$. D'où cette image d'une grandeur pleine et entière, d'une magnitudo qui finit par caractériser, chez les orateurs appelés à définir les mots de la loi, cela même dont l'amplitude ne devait jamais décroître ${ }^{84}$. Non que les Romains de la République tardive eussent perdu la conscience du sens relatif de " prééminence " à l'intérieur d'un rapport hiérarchique, lié à maior, qui faisait toute l'originalité de l'antique concept; ni qu'ils eussent effacé sa valeur comparative ou superlative en employant à sa place d'autres termes, magnitudo et amplitudo, qui n'impliquaient aucune mise en relation avec rien d'extérieur à eux. Bien au contraire : le crime instaurait en définitive une absolue supériorité de cette référence sur les Romains eux-mêmes, subordonnés par rapport à elle et tenus de la respecter. Mais il leur fallait bien se représenter sous la figure d'une mesure inentamable et imaginer comme quantité ce qui n'avait d'existence en droit que par la défense de le réduire. La maiestas n'apparaissait comme "grandeur" que parce qu'elle était maintenue par la loi.

80. Verba legis de la lex Appuleia dans De oratore, 2, 107 ; de la lex Cornelia : Verr., 2, 1, 84 ; Asconius, Corm., p. 61, Clark. ; Quintilien, Inst. or., 4, 4, 8 ; de la loi de César : Phil., 1, 21.

81. Lex Iulia : les fragments compilés au Digeste n'ont conservé que des listes de faits constitutifs, introduits par la formule "quo tenetur is, qui ». Cependant, Marcianus, Dig., 48, 4,3 , emploie la tournure " maiestatem publicam laedere" (cf. PAPINIEN, 4, 8, laesae maiestatis) : cette expression a pu être utilisée dans le corps de la loi, sans nécessairement servir à qualifier le crime à titre principal (laedere maiestatem est attesté par VALĖRE MAXIME - 6, 3, 3 - et par les controverses de SENÉQUE le Rhéteur, lesquelles peuvent transmettre une terminologie tardo-républicaine : 9, 2 ; of. Laedere rempublicam : 10, 4 et 10,5). TACrre, An., 1, 72, rapporte à la loi elle-mème la formule "si quis [...] maiestatem populi Romani minuisset ". Sous l'empire, on continue d'employer minuere maiestatem, à côté de laedere, jusqu'au Iv siècle (par ex., Aмmien, 14, 5, $4 ; 29,2,2$ ). Rien n'appuie l'hypothèse d'A. N. SHERwiN WHITE, op. cit. supra n. 1, p. 290, qui suggère la présence d'une clause supplétive " quive quid fecerit quo populi Romani maiestas minueretur" dans toutes les lois de majesté.

82. Cicéron, Part. or., 105 ( $m$. autem aucta potius quam deminuta). Cf. l'argumentation dans le procès de Popilius : Her., 1, 25; 4, 34-35; Inv., 2, 72-73 et "(maiestatem) auxisti" dans Fam., 3, 11, 3, à propos de l'accusation contre Claudius Pulcher en 50. Dans TrTe-LIVE, $6,40,4$, "aucta potius quam imminuta maiestas eorum" (c'est-à-dire des familles patriciennes) me paraît être le réemploi d'un topos issu de la rhétorique judiciaire.

83. Orator, 102 : « dans le procès de Rabirius, toute la cause porta sur la définition juridique de ce qu'est maintenir la majesté ", ius omne retinendae maiestatis Rabirii causa continebatur.

84. Voir supra n. 13. 


\section{L'INFINITUDE DE L'INTERDIT}

Sous le coup de la loi tombaient des transgressions qui n'atteignaient pas le peuple Romain directement, mais une référence qui le doublait en hauteur. D'après la qualification légale du crime, ce n'était pas à proprement parler le populus, la res publica ni la civitas, qui se trouvaient diminués, mais leur majesté ${ }^{85}$. Sous la sauvegarde de l'interdit, la loi plaçait la grandeur des institutions, instaurant au-dessus d'elles et de leurs conditions d'existence concrètes la sanction de leur propre dépassement. Une fois de plus, il ne s'agit pas d'une simple question de mots. Soyons attentifs plutôt aux mécanismes qui se mettent en place par le truchement de ces minutieuses constructions verbales. Car on voit ainsi qu'accède au statut d'inviolabilité une zone virtuellement indéfinie, sans limites arrêtées d'avance et susceptible d'augmenter pour le besoin de poursuites nouvelles. Bien sûr, les lois de majesté avaient l'une après l'autre précisé certains faits constitutifs du crime. Les catalogues légaux en regroupaient par affinité les principaux traits. Mais ces énumérations n'avaient qu'une valeur casuistique d'exemple. Le domaine d'incrimination ne fut jamais une fois pour toutes circonscrit par elles. L'histoire romaine du crimen comme beaucoup plus tard dans les états de l'Occident latin, du XII ${ }^{e}$ au $\mathrm{xv}^{\mathrm{e}}$ siècle - obéit à une logique d'élargissement continu du cercle des délits compris sous son enseigne. Histoire du pouvoir sur la très longue durée, et où il faut voir, mieux qu'on ne le fait habituellement, une construction institutionnelle qui ne cesse de réemployer des matériaux plus anciens, comme s'il s'agissait en permanence du même édifice.

À Rome, le développement de cette structure se suit surtout pendant l'Empire, à travers les techniques - procédurales et policières - grâce auxquelles un pouvoir monarchique mais non dynastique tentait de s'assurer le contrôle de sa propre durée. Par une propagation du cercle d'inculpation dont l'empereur a la maîtrise, la Majesté poursuit son avancée à travers les canaux de la procédure, sur la scène secrète de l'enquête pénale où, d'une manière beaucoup plus efficace qu'on ne le suppose ordinairement, le pouvoir déploie sa stratégie d'investissement du champ politique. On ne s'étonnera pas de constater que sous la République,dont il est ici question, ce mouvement ait été à peine amorcé : l'accusation de

85. À noter cependant l'emploi fréquent de laesa res publica chez les rhéteurs (SÉNÈQE, Contr., 5, 7; 10,1, 13;10,4;2, 21 ; Quintilien, Decl., 240;326; Decl. maiores, 12) et les emplois d'imminuere avec un autre objet que la majesté (ainsi, "imminuere sacra" dans Asconius, p. 21, Clark ou imminuere ius legationis dans II, Verr., 1, 84, etc. (Ps. Asconius, ad $l o c$ : " celui qui n'a pas défendu son pouvoir dans l'administration de son office est coupable de diminution de la magistrature, pour ainsi dire de lèse-majesté ", imminuti magistratus veluti maiestatis laesae reus est. 
majesté n'était pas et ne pouvait être le moyen de contrôle centralisé qu'elle devait devenir plus tard, tout simplement parce que, si oligarchique qu'il ait été, le régime républicain restait un régime de compétition relativement ouverte : de quelques familles dominantes à une famille régnante, la différence (du moins pour ce qui est d'une histoire du pouvoir lui-même) n'est pas de degré, mais de nature. Pourtant, il nous reste quelques indices, dès l'époque républicaine, d'une extension de la loi à des faits d'une nature nouvelle. Il vaut la peine d'y prêter quelque attention, parce que précisément ces premiers développements du crimen maiestatis ne doivent encore rien à la transformation de la structure politique et s'inscrivent dans la logique d'un concept dynamique, doué si l'on peut dire d'une capacité à élargir son emprise.

Les données sont ténues, mais déjà significatives. Dans certains cas, il ne s'agissait encore que d'une simple interprétation compatible avec l'esprit du texte. En 66, Caius Manilius est accusé de maiestate : comme tribun, il avait fait voter sous l'émeute une loi favorable aux affranchis, en laissant occuper les abords du Capitole par une troupe de manifestants esclaves. Or un tel cas de figure n'avait probablement pas été régi par la lex Cornelia : Sylla avait, en effet, aboli toute initiative tribunicienne des lois. Mais ce droit ayant été restauré en 70 , sous le consulat de Crassus et Pompée, il redevint normal d'étendre aux tribuns de la plèbe un type d'incrimination qui frappait sans doute les comportements séditieux des autres magistrats ${ }^{86}$. Dans d'autres cas, on attribuait à la loi de véritables nouveaux délits. Ainsi, toujours en 66 , à l'encontre du tribun Cornelius : la lèse-majesté avait consisté pour lui à passer outre à l'intercession d'un tribun de la plèbe en poursuivant lui-même la lecture d'un projet de loi, à la place du héraut qui en était empêché. Il n'y avait eu ni sédition ni violence, mais les accusateurs soutinrent qu'avait été diminuée la maiestas du peuple à cause de l'obstacle mis à la majesté du tribun intercesseur. Devant le jury, on disputa sur l'étendue du concept légal, que la défense limitait aux faits expressément énoncés par la loi et que l'accusation prétendait ouvrir largement par libera interpretatio ${ }^{87}$. Celle-ci était assurément facilitée du fait que, depuis le commencement du siècle, dès qu'il s'était agi d'interpréter les mots minuere maiestatem de la loi d'Appuleius Saturninus, les orateurs en avaient proposé et fixé d'emblée l'acception la plus large, c'est-à-dire la moins concrètement déterminée : "retirer

86. Références supra $\mathrm{n} .68, \mathrm{n}^{\circ} 5$.

87. Asconius, In Comelianam, p. 61 et 62, Clark; Quintilien, Inst. or., 4, 4, 8. R. A. BAUMAN, op. cit. supra n. 16, p. 71 sq., croit que le crimen consista pour le tribun à lire la loi à la place du héraut dont c'était le métier, et à rabaisser par là la maiestas de sa propre magistrature; en réalité, c'est la $\mathrm{m}$. du tribun intercesseur que cette obstination diminue : voir E. S. Gruen, The Last Generation of the Roman Republic, Berkeley, 1973, p. 264 sq. 
quelque chose de la dignité, de la grandeur ou de la puissance du peuple Romain ou de ceux auxquels le peuple a conféré un pouvoir "; "grandeur et dignité de la cité »; « dignité de l'empire et du nom Romains », etc.

Dans les dernières décennies de la République, l'interprétation libre se développa essentiellement dans les écoles des rhéteurs. On travestit d'abord des causes réelles jugées avant la loi de 100 , pour les ramener à l'unité du crime de majesté. Caius Popilius, par exemple, avait été condamné par l'assemblée du peuple au cours d'une procédure tribunicienne de haute trahison : légat du consul Cassius Longinus en 107, il avait après une défaite livré des otages et abandonné des armes aux Gaulois, en échange d'une retraite. Vers les années 80 , les gens d'école traduisent la dispute en ces termes : a-t-il « diminué la majesté », ou ne l'at-il pas plutôt maintenue en épargnant par cette concession la vie de ses hommes ${ }^{88}$ ? Mais on imagina surtout des procès fictifs pour multiplier les hypothèses. Les controverses de Porcius Latro, qui reprennent dans la seconde moitié du dernier siècle avant notre ère des sujets probablement antérieurs, incluent ainsi les désastres militaires dans les affaires de majesté : destruction des enceintes, incendie de la flotte, perte de l'armée ${ }^{89}$. Autre thème, débattu encore autour des années $80:$ le père du tribun Flaminius, en 232, avait-il " diminué la majesté » en forçant son fils à quitter la tribune aux harangues, d'où il proposait une loi agraire " contre la volonté du sénat et par sédition" - et en opposant ainsi à la puissance tribunicienne de son fils, "pouvoir public", sa propre puissance paternelle, "pouvoir privé " ${ }^{90}$ ? Le consul Flaminius, en 192, n'avait-il pas " offensé la majesté du peuple Romain " en offrant à sa maîtresse ou à son mignon, au cours d'un banquet, le divertissement d'une exécution capitale ${ }^{91}$ ? Jusqu'où le détenteur d'une magistrature pouvait-il aller dans ses plaisirs singuliers sans altérer la maiestas de son office? Que juger si un consul s'était rendu au lupanar en grande pompe, précédé de ses licteurs? si un préteur avait dit le droit en habit de femme? L'imputation de " soustraire à la grandeur du peuple Romain "

88. Rhet. Her., 1, 25; Cicéron, De inv., 2, 73. Qu'il se soit agi d'un procès de perduellio a été montré par C. H. BreCHT, op. cit. supra n. 66, p. 291, n. 19, sur la base de CiCÉron, De legibus 3, 36.

89. SÉn., Contr., 10, 4, 11 ; cf. 5, 7 : avoir laissé l'ennemi massacrer les prisonniers de guerre.

90. De inv., 2, 57 (Valère Maxime, 5, 4, 5, dépend d'une source qui n'avait pas encore intégré la fiction de ce procès). Voir l'amplification de ce casus dans DENYS D'HaLiCARnasse, 2, 26, 5 ; voir aussi QuinmLIEN, Declamation 202, p. 30, RITIER : si magistratus erit (pulsatus), crimen maiestatis obligabitur. Sur la portée juridique du heurt entre les prérogatives du droit paternel et le droit public dans l'exemplum de Flaminius, Y. Thомas, " Droit domestique ", MEFRA, 1982, p. 543 sq. et "Vitae necisque potestas", dans Du Châtiment dans la cité, Ec. Fr. Rome, 1984, p. 525 sq. Cf. également, G. Lobrano, Pater et filius eadem personna. Per lo studio della patria potestas, Milan, 1984, p. 110 sq.

91. Seneque, Contr., 9, 2. 
n'exigeait-elle pas au surplus que l'on distingue, parmi les crimes commis " in magistratu ", ceux qui n'engageaient pas la fonction elle-même, mais seulement le citoyen qui la revêtait - par exemple, tuer son père, empoisonner son épouse ou corrompre une matrone par adultère ${ }^{92}$ ? l'inverse, n'était-il pas vrai qu'un simple particulier, en dehors de tout magistère, était capable de porter atteinte à la majestas populi Romani, même s'il s'agissait d'une femme, telle Claudia, qui avait osé exprimer tout haut le souhait qu'une défaite vienne saigner la populace de Rome, un jour où son chariot s'était trouvé pris dans un encombrement de foule ${ }^{93}$ ?

Cependant, c'est seulement depuis le régime mis en place par Auguste que s'impose dans les faits une interprétation du crimen maiestatis déliée de toute attache avec le texte légal. À partir du $\mathrm{i}^{\text {er }}$ siècle de notre ère seront incriminés les complots et les projets, les actes et les paroles, les libelles, l'impiété envers le prince, les offenses à son image, la divination concernant l'Empire, la magie. Sans doute a-t-il fallu une transformation radicale du pouvoir - l'instauration d'une monocratie, dont aujourd'hui l'historiographie a tendance à relativiser la rupture par rapport au régime de la république oligarchique - pour que l'instrument mis au point durant les dernières décennies avant notre ère soit employé à étendre sans limites réglées le champ du procès politique. Les accusations lancées à l'initiative du prince, c'est-à-dire par ses agents de renseignement, l'organisation de la délation, l'emploi de la torture pour contraindre à l'aveu, bref l'introduction des premiers éléments d'une pratique inquisitoriale, bientôt l'enquête d'office imposée comme mode de poursuite politique avant d'être généralisée aux crimes de droit commun, toutes ces techniques nouvelles apparues sous l'Empire (et certaines dès les règnes d'Auguste et de Tibère) ont permis un extraordinaire progrès de l'inculpation - et, par là, une intensification sans précédent de la surveillance politique, un élargissement de son emprise sans commune mesure avec la faiblesse de ses moyens administratifs et policiers. Ce n'est pas ici le lieu d'examiner ce redéploiement du dispositif criminel, qui est bien sûr le résultat d'une occupation de la scène judiciaire par le pouvoir cen-

92. Senk̀ue, Contr., 9, 2, particul. 11 sq. Nombreux thèmes aussi chez Quintilien, où la fantaisie est poussée jusqu'aux limites de l'absurde, selon la loi du genre : un citoyen subvertit l'ordre public en recueillant chez lui les jeunes gens chassés par leurs pères ( $D e c l$., 240); un légat prend le risque de laisser durer une épidémie, en tenant secret l'oracle qui lui recommandait d'immoler son fils (Decl., 326); un légat chargé d'acheter du blé pendant une famine en acquiert deux fois plus, mais trop tard pour éviter que les citoyens ne se nourrissent de cadavres (Decl. maiores, 12).

93. SÉNĖQUE, Contr. $9,2,13$ : privatus potest accusari maiestatis laesae, si quid fecit quo maiestatem populi Romani laederet; cf. QuINTILIEN, Inst. or., 5, 8, 39 : " iniuriam fecisti, sed, quia magistratui, maiestatis est. " La tradition, rapportée par SuETone (Tibère, 2, 7), d'un procès de majesté contre Claudia en 246 remonte probablement à un exemple d'école. 
tral, la marque propre de son irruption : il appartient à l'histoire du droit de l'Empire. Mais il eut aussi pour outil un chef d'inculpation, la majesté, qu'il fallait pouvoir penser comme infiniment extensible. La praxis institutionnelle fait du concept un instrument : c'est la conception de cet instrument, de provenance républicaine, qui m'importe ici.

Il fallait que l'interdit fût formulé comme indéfini et que l'aire de protection pénale du pouvoir politique perdît tout contour concret. Or les locutions de la langue du droit procèdent à certaines contractions par lesquelles s'exprime l'indétermination du crime. La première consiste à oblitérer le verbe qui définit l'action. La seule indication d'une loi de majesté ou d'un crime de majesté fait silence sur les circonstances du passage à l'acte et, en escamotant ses diverses modalités (comme " diminuer ", " endommager ", " attaquer ", " violer », etc., verbes sur lesquels une interprétation prend plus facilement appui), rend l'idée de la transgression aussi abstraite qu'est imprécise l'idée même de ce qu'elle transgresse $^{94}$. «On l'accuse de majesté » : expression des plus courantes chez les orateurs républicains et chez les historiens de l'Empire ${ }^{95}$. Cette prétérition reflète sans doute un langage de procédure. On l'entrevoit à tel détail fourni par une lettre de Cicéron : en 54 av. J.-C., Aulus Gabinius doit rentrer précipitamment à Rome, sous l'injonction d'un édit de comparution " du chef de majesté » ${ }^{96}$. L'acte d'accusation, bien sûr, audessous de la désignation du crime, indiquait brièvement les faits mis en cause, afin que l'accusé pût organiser au mieux sa défense ${ }^{97}$. Mais l'ambiguîté même du nom rendait plus facile que pour aucun autre crime de subsumer tout agissement - actes, paroles, pensées - sous son enseigne. Le sacrilège, le parricide, l'homicide, l'inceste, l'adultère, la brigue, la concussion, le péculat définissaient l'infraction elle-même, en sorte que les faits rapportés à leur titre apparaissaient comme leur mise en œuvre (sous le chef d'homicide, on était nécessairement accusé d'avoir tué un homme; sous le chef de sacrilège, d'avoir volé un objet consacré, etc.); le nom de la majesté, au contraire, laissait planer un étrange silence sur la nature de l'attentat à propos duquel elle était invoquée.

L'attentat restait implicite. Il se résorbait dans la chose même à quoi la loi réservait sa défense, comme si c'eût été s'en réclamer et la proclamer

94. Les lois ne sont pas citées comme « imminutae " ou " diminutae maiestatis ", mais seulement comme "maiestatis ». Lex Cornelia : Cickron, Pis., 21, 50; Asconius, p. 59-60, Clark. Cette appellation tronquée vaut aussi pour la lex Iulia, que nous ne connaissons que sous l'appellation " maiestatis " au Digeste et au Code ou chez les auteurs.

95. Accusare maiestatis ou de maiestate : Ad Quint. fratr., $3,1,25 ; 3,2,3$; condemnari maiestatis (pro Cluent, 97; 99), etc. Cf. TACrre, An., 2, 50;3, 22;3,38;3, 67;3, 70;4, 19;4, 30; 4, 31; 4, 42; 6, 9; 6, 18; 6, 47; 14, 48; Pline, Pan., 42; Tertullien, Apol., 10, 1, etc. 96. Ad Quint. fratr., III, 1, 24.

97. SP, V, 16, 14. T. MommSEN, Droit pénal, II, 57. 
que d'avoir eu affaire à elle par le moyen du crime - un peu comme s'il eût été question de " crime de chose sacrée " pour le sacrilège, de " crime de pureté » pour l'inceste ou, pour le meurtre, de "crime de vie ». Mais la formulation est aussi abstraite en un autre sens : il n'est pas toujours dit de quoi ni de qui la maiestas est la grandeur inviolable. Bien sûr, le peuple Romain, plus tard le prince, en sont implicitement les sujets. Mais il reste que l'inachèvement, l'incomplétude dans l'expression de l'objet du crimen opère un détournement subreptice de sens, puisque la valeur comparative ou même superlative du mot n'étant plus rapportée à aucun terme, il devient possible de l'imaginer sans contrepartie, dans l'absolu. Au départ, il ne s'agissait encore que d'isoler les termes légaux soumis à l'exégèse : le travail interprétatif portait sur "diminuer la majesté ", sans complément nécessaire ${ }^{98}$. Mais à l'arrivée, c'est-à-dire aussitôt qu'il fut politiquement utile et juridiquement possible (dans la mesure où les interprétations impériales s'imposaient) de dégager le syntagme de tout contexte pour en libérer l'extension, son abstraction devint une arme au service de l'inculpation généralisée. En 2 av. J.-C., par exemple, Auguste qualifie les adultères avec sa fille de "violation de la majesté $"{ }^{99}$. À partir de 12 , les mots et les écrits contre le prince ou contre ses proches deviennent des blasphèmes, étant "prononcés contre la majesté » ${ }^{100}$. "Contre la piété religieuse" mais aussi «contre la majesté », apparaissent, dans les rescrits impériaux, certaines formes d'atteinte à l'intégrité des images impériales ${ }^{101}$. Contre la majesté, également, la consultation d'astrologues au sujet du destin de l'Empire et du monarque ${ }^{102}$.

Au départ de l'histoire de la majesté, on s'en souvient, aucune métaphysique ne vient majorer le substrat politique romain. Nul écart ne sépare la chose même de sa grandeur. Pourtant, la maiestas du peuple, de la République, de l'Empire, leur apporte une amplification dont le processus est constant. Le mouvement présumé qui porte l'entité politique romaine à s'étendre, à s'élever toujours plus dans l'échelle des supériorités, l'exhausse jusqu'au niveau où, dans son dépassement, elle finit par 105.

98. Ainsi, Ad Her., 1, 12, 21 ; 2, 12, 17; CiCÉRON, De inv., 2, 52 ; De orat., 2, 201 ; part. or.,

99. TACrTE, An., 3, 24, 2.

100. TACITE, $A n ., 1,72,3$, cf. 4,31 , sermo adversum maiestatem. Sur $A 4,34$ et la possibilité d'une règle associant la maiestas d'Auguste et celle de César divinisé, voir supra n. 73.

101. Par exemple, les réponses négatives (qui dans d'autres cas étaient positives) de Tibère, TACITE, An., 1, 73: nec contra religiones fieri ou de Septime Sévère et Caracalla, Digeste, 48, 4, 5 : nec contra maiestatem fieri (les accusations de majesté pour crime d'image étant très bien attestées dès les règnes d'Auguste et de Tibère, par ex. Édits d'Auguste à Cyrène, II, 1. 52 sq., dans FIRA, I, p. 408, ou Tacite, An., 1, 74 et 3, 70, cf. Suftone, Tib., 58).

102. Le crimen maiestatis pour faits de divination sur le sort du prince est très bien attestée dans l'antiquité tardive : mais une telle qualification apparait déjà en 20 , sous Tibère (TACITE, $A n ., 3,22,2)$ et même en 16 ( $A n ., 2,27,1:$ res novae). 
s'abstraire hors d'elle-même et par s'effacer derrière sa grandeur. Mais cette élévation ne suffit encore pas à assurer à la grandeur sa position de lieu politique ultime, sa valeur de référence au-delà des institutions qu'elle rehausse. Son excellence n'est encore que d'être le principe de leur essor. Pour que sa culmination franchisse l'écart qui la détache de son substrat, il fallait que la loi eût tranché le lien qui les confondait l'un avec l'autre, en plaçant le corps politique sous la légitime sauvegarde de la majesté. Cette rupture s'opère avec l'interdit du crimen maiestatis, lorsque les anciens attentats contre la chose publique sont uniment qualifiés de crimes contre la majesté, vue comme extensible, de cette chose. Alors ce qui n'était qu'un mode d'être, qu'une condition de l'existence politique concrète, caractérisée d'une manière que l'étymologie rend pour ainsi dire transparente, s'érigea en zone réservee, distante des institutions dont elle servait la défense. La Majesté devint à son tour, sauvegarde de toutes les autres, une institution.

\section{L'INSTITUTION DE LA MAJESTE}

Au cinquième livre des Fastes, à propos du mois de mai, Ovide tire d'une réflexion sur la valeur sémantique de maius une véritable mise en scène de la Majesté, élevée dans l'Olympe et gardienne - pour la première et unique fois dans la littérature latine, on s'en souvient - de Juppiter. G. Dumézil s'est appuyé sur ce texte pour montrer la conscience claire que les Romains conservaient encore au commencement de notre ère de l'étroit rapport entre maiestas et maior; et pour répudier ce faisant l'interprétation de certains latinistes, tels $\mathrm{H}$. J. Rose et $\mathrm{H}$. Wagenvoort, qui voyaient derrière ce concept, comme derrière bien d'autres termes du vocabulaire institutionnel romain, imperium, auctoritas, gravitas, le témoin fossilisé d'une pensée de type magico-religieux. On croyait déceler facilement, dans les années quarante et cinquante, les traces d'une représentation du pouvoir dans laquelle êtres et choses rayonnaient d'une force mystique assez comparable au trop longtemps célèbre mana des Mélanésiens - et la majesté latine n'a pas échappé à ce traitement ${ }^{103}$. Seulement, pour restaurer les anciens Romains dans la dignité d'une pensée rationnelle et arracher la maiestas à l'univers diffus du primitivisme, Dumézil passe sous silence un trait essentiel de la majesté, étranger à

103. H. WAgenvoori, op. cit. supra n. 15. La critique de la thèse de H.J. Rose est reprise notamment dans Religion romaine archaïque, op. cit. supra n. 19, p. 33 sq. et dans Idées romaines, op. cit. supra n. 1 , p. 125 sq. 
l'étymologie, certes, mais indissociable de sa position juridique nouvelle, telle que précisément Ovide la comprend : sa position de garant externe, qui excède de loin le contenu positif de l'idée hiérarchique; son élévation en zone interdite, qui lui confère bien plus qu'un « rayonnement » venu par surcroît estomper la clarté du sens original. Sans doute, maior sert-il de support à l'allégorie où Maiestas est reine. Cependant, au-delà du sens qui s'attache au mot, se déploie aussi l'institution juridique où le mot prend corps : l'institution de la Majesté. Voici le texte (Fastes 5, v. 11-50) :

«Après le Chaos, quand pour la première fois le monde eut reçu ses trois éléments

Et que toute la matière se fut divisée en espèces nouvelles,

La Terre, entraînée par son poids, descendit dans les régions inférieures et entraîna les eaux avec elle.

Le Ciel, par sa légèreté, se plaça au plus haut;

Avec lui le soleil et les étoiles, que nulle pesanteur ne retenait,

Ainsi que vous, coursiers de la Lune, bondirent.

Mais ni la Terre ne respecta longtemps la prééminence du Ciel, ni les autres astres celle de Phébus :

Tous les degrés d'honneur étaient égaux.

Souvent ô Saturne, sur le trône que tu occupais,

Quelque divinité issue de la plèbe osa s'asseoir;

Aucun dieu étranger ne daignait faire escorte à Océan

Et Thétys, souvent, se retrouva reléguée à la dernière place.

Enfin, Rang (Honos) et Révérence (Reverentia) au maintien décent, au visage paisible

Soumirent leurs corps aux obligations d'une couche légitime.

De là fut engendrée Majesté. C'est eux, déesse, qu'elle a reconnu comme ses parents

Et, du jour même où elle naquit, elle fut grande.

Sans délai, elle vint s'asseoir au milieu de l'Olympe, la tête haute,

Couverte d'or, admirable à voir dans sa robe de pourpre.

À ses côtés prirent place Pudeur et Crainte, et l'on aurait pu voir

Tous les dieux régler leur conduite sur la sienne.

Aussitôt entra dans les esprits le respect des dignités;

Ceux qui le méritent sont appréciés et chacun cesse de se préférer aux autres ;

Cet état de choses subsista dans les cieux pendant de longues années

Jusqu'au moment où le dieu vieillard (Saturne) fut précipité par les destins du haut de la citadelle;

La Terre enfanta les Géants, descendance farouche, monstres énormes

Qui allaient avoir l'audace d'attaquer la demeure de Juppiter.

Elle leur donna mille mains et des serpents au lieu de jambes

Et dit : contre les dieux grands, tournez vos armes!

Déjà ils se disposaient à entasser les montagnes jusqu'au plus haut des astres 
Et à provoquer au combat le grand Juppiter.

Mais Juppiter, lançant la foudre de la citadelle du ciel,

Renverse ces poids immenses sur ceux-là mêmes qui les avaient déplacés.

Efficacement défendue par les dieux, Majesté

Subsiste, et depuis ce temps son culte demeure.

Elle est assise près de Juppiter, elle est le plus fidèle des gardes de Juppiter Et assure à Juppiter son sceptre qui se fait craindre sans recourir à la violence.

Elle est aussi descendue sur terre : Romulus et Numa l'ont honoree Puis d'autres, chacun selon son temps.

C'est elle qui assure aux pères et mères le respect pieux qui leur est dû ;

Elle qui est la compagne des jeunes garçons et des vierges,

Elle qui recommande les faisceaux et l'ivoire curule,

Elle qui se tient debout sur le char des triomphateurs, attelé à des chevaux couronnés. »

Dans ce tableau de mythologie politique sur fond de guerre des Géants, Maiestas assure l'échafaudage des pouvoirs, depuis Juppiter jusqu'aux chefs de famille en passant par les rois et les magistrats détenteurs d'imperium. Revêtue de pourpre et d'or, elle garantit le trône et le sceptre, elle sacralise les faisceaux des licteurs, le siège curule, le char des triomphateurs : bref, les ornamenta. En retour, les pouvoirs sont au service de la déesse; leurs armes la défendent, elle qui les cautionne sans armes. La foudre renverse les rebelles montés à l'assaut des puissances célestes, et cette victoire maintient son culte inentamé. Ce n'est pas seulement que Juppiter, les rois et les magistrats jouent sur le double tableau de la guerre et du droit, de la sauvegarde par les armes et par l'obéissance. Ovide représente aussi la fiction selon laquelle le pouvoir, se prenant lui-même pour objet, se subordonne à une référence suprême pour qualifier d'attentat contre elle tout attentat contre lui. Ce partage fait que ce qui l'atteint devient un crime contre la Majesté en personne. Pour sa défense, il se dresse paré des insignes qui font voir la dignité de l'office qu'il revêt. Les uns sont traditionnellement ceux des magistrats républicains. D'autres figurent depuis le règne d'Auguste, sur les médailles et les monnaies, l'élection jupitérienne du prince : le sceptre que, sur une gemme du musée de Vienne, Auguste tient de la main droite, assis, l'aigle divin à ses pieds (mais qui dans les monnayages des deux premiers siècles restera plutôt l'attribut du dieu lui-même, gravé au revers de la pièce qui porte l'empereur à l'avers, ou bien montré dans le geste de le couronner) ${ }^{104}$; la foudre, sur laquelle Octave se dresse debout ou que l'on voit

104. Sceptre : T. Mommsen, op. cit. supra n. 28, 2, p. 62 sq. ; A. AlfÓld, op. cit. supra n. 42, p. 228 sq. Sur la Gemma Augustea, J. R. FeARS, op. cit. supra n. 18, p. 207. Pour Auguste, il faut ajouter la référence à Tertullien, De anima, 46, 7 (rêve d'Octavius le père, voyant son fils en présence de Juppiter armé de la foudre et du sceptre). Monnaies: 
orner sa tête, sur les deniers frappés après la victoire d'Actium (elle deviendra un insigne jupitérien du prince dans les monnaies impériales) ${ }^{105}$. La Majesté elle-même est parée. La pourpre, couleur du paludamentum des généraux sous la République, semble s'être intégrée au rite d'investiture impériale dès le $r^{\text {er }}$ siècle : elle avait déjà été le privilège de César, et Octave en réglementa l'usage en 36, anticipant une abondante législation qui assimilerait le port interdit de la pourpre à la lèsemajesté. L'or est réservé très tôt également à un monopole impérial : l'or tissé dans les vêtements, mais aussi l'or des sièges, des statues, des couronnes ${ }^{106}$.

Dans un tel montage, on voit bien que le rapport de hiérarchie n'est plus l'essentiel. Bien sûr, l'abstraction personnifiée forgée sur maior incarne une structure politique où les degrés d'honneur sont maintenus à bonne distance. Un ordre légitime de dignités inégales s'agence jusqu'au dieu qui emploie ses armes à le maintenir. Mais au-delà de ces dignités mêmes et du pouvoir qui les défend, Majesté prémunit l'ensemble derrière sa propre inviolabilité. Lois et armes assurent le service de sa Grandeur tutélaire, son patronage les sanctifie. On songe à nouveau, à plus de cinq siècles de distance, à la formule de la constitution Imperatoriam maiestatem de Justinien :

" que la majesté impériale reçoive l'ornement des armes et l'arme des lois, afin que le prince Romain puisse commander à la guerre comme à la paix et ressorte vainqueur aussi bien dans ses combats contre l'ennemi que par les voies légitimes en repoussant les iniquités, et qu'en sa religion du droit il excelle autant qu'en ses triomphes."

Ovide avait rédigé le cinquième livre des Fastes avant 8 de notre ère. En septembre 14, les funérailles d'Auguste se présentent comme un véritable rite triomphal de la Majesté. Parmi les honneurs que le sénat décréta pour le prince, il fut décidé que le convoi emprunterait la porte triomphale et que « des panneaux où étaient inscrits les titres de ses lois, ainsi que les noms des peuples qu'il avait vaincus, seraient portés en tête

H. Cohen, Monnaies frappées sous l'empire romain, rééd, Paris, 1955, Néron, $\mathrm{n}^{\circ} 118-119$; Trajan, $0^{\circ} 249$; Hadrien, n' 859 et drachmes d'Alexandrie, JEA, 47, 1961, p. 129.

105. Foudre: A. Alfóld, op. cit. supra n. 42, p. 338 sq. H. MATmingly, Coins of the Roman Empire in the British Museum, Londres, depuis 1926 : Octave, $n^{\circ} 628$ et 637 . Caligula paraitra en public " fulmen tenens" (SuErone, Calig., 52) et Domitien se fera représenter ainsi sur une monnaie (Mattingly, $n^{\circ} 381$ ). Trajan : Mattingly, $n^{\circ} 249,825,899$ et attique de l'arc de Bénévent, représentant la traditio fulminis de Juppiter à Trajan, J. R. FEARS, op. cit. supra n. 18, p. 238 sq. Hadrien : Mattingly, $n^{\circ} 242$.

106. Pourpre : T. MoMmsen, op. cit. supra n. 28, 2, p. 72 sq.; R. Alfoldi, op. cit. supra n. 42, p. 167 sq. ; M. ReInhold, History of Purple as a Status Symbol in Antiquity, Bruxelles, 1970, p. 128 sq. Or : Alfoldi, p. 176 (vêtements), p. 243 (siège de César). Cf. le brocard de pourpre et d'or et la statue dorée d'Auguste, infra n. 110. 
du cortège $"{ }^{107}$. Le passage par la porta triumphalis assurait que les funérailles impériales seraient comprises par tous comme la célébration d'un triomphe ${ }^{108}$. Des trois effigies de l'empereur, la première, qui surmontait la litière d'ivoire et d'or recouverte d'un brocard de pourpre et d'or sous lequel son corps était caché, le montrait en costume de triomphe; la seconde était dorée; la troisième était dressée sur un char triomphal ${ }^{109}$. Une statue de la Victoire précédait l'ensemble ${ }^{110}$. Mais plus encore, en avant du cortège, les titres des lois et les vocabula des peuples vaincus, inscrits probablement au bas d'écussons qui les représentaient allégoriquement - comme l'indique Dion Cassius et comme on le voit encore aux funérailles de Pertinax en $193^{111}$ - laissaient imaginer que dans ce triomphe funèbre était célébrée la Majesté tutélaire du prince, processionnant dans Rome sous l'emblème croisé des arma et leges, sous l'ornement des armes et sous les armes des lois.

Le décor ovidien (dont les idées personnifiées, s'il n'est pas trop audacieux de les en rapprocher, trouvent un ornement dans le triomphe funèbre du premier princeps) nous plonge dans une imagerie politique qui donne de l'apparence à quelque chose d'invisible et d'inexistant : à l'intangibilité d'une grandeur établie en institution extrême, en interdit posé contre le crime de lèse-institution; en limite, également, bornant l'horizon d'un pouvoir subordonné, selon la formule transmise par la lex de imperio, à la "majesté des choses divines et humaines " (c'est-à-dire, on s'en souvient, à l'éminence des lois). La majesté, telle qu'elle était constituée à la fin de sa longue histoire républicaine, aborde ainsi sous l'éclat d'une représentation son premier moment impérial. Mais cette illusion, qui prête le contour d'une figure à ce qui n'a ni contenu ni contour - et qui n'est à proprement parler pas représentable ${ }^{112}$, nous

107. An., 1, 8, 4 .

108. Ps. Aurelius Victor, Ep., 13, 11 ; SHA Hadrien, 6, 3; Senèque, Ad Marciam, 3, 1. J. C. Richard, «Les funérailles des empereurs romains », $A N R W, 16,2,1978$, p. 1129 sq. ;

J. ARCE, Funus imperatorium : los funerales de los imperarores romanos, Madrid, 1988.

109. Dion Cassius, 56, 34, 2.

110. SuEtone, Aug., 100, 4.

111. Dion Cassius, $56,34,3$, cf. 74, 4, 6. Sur les tituli des gentes en général, voir C. NicoLET, L'Inventaire du monde, op. cit. supra n. 56, p. 61 sq.

112. L'historien des cérémoniels et des figurations politiques a tout intérêt à méditer sur le lien de nature logique (et non, comme on le pense souvent, de nature idéologique) entre institutions et esthétique, à partir notamment des réflexions de Pierre LeGENDRE sur la communication de l'irreprésentable par les images (notamment dans Leçons II. L'empire de la vérité, Paris, Fayard, 1983, et Leçons IV. L'inestimable objet de la transmission. Étude sur le principe généalogique en Occident, Paris, Fayard, 1985, p. 53 sq.; 197 sq. Réflexions qui me paraissent confortées par l'étude la plus intelligente et la plus stimulante écrite jusqu'à ce jour sur l'esthétique politique à Rome : P. VEYNE, « Propagande expression roi image idole oracle ", L'Homme, 114, avril-juin 1990, XXX (2), p. 7-26 = La Société romaine, op. cit. supra n. 16, p. 331-337. 
servira ici à faire retour sur la construction juridique dont maiestas occupe le sommet, pour comprendre ce qu'elle n'est pas.

La sanction par la loi d'une référence politique ultime eut pour conséquence un réaménagement des catégories du droit public romain. Les institutions de la République n'offraient traditionnellement pas prise à la souveraineté au sens moderne. Or l'instauration d'un pôle d'inviolabilité autour de la notion de grandeur eut pour résultat d'introduire quelque chose d'équivalent, mais par la voie négative. Il ne pouvait exister de souveraineté - d'imputation de toutes les décisions politiques à un centre unique - dans un système où les pouvoirs de chaque organe avaient un fondement autonome. L'imperium des magistrats avait sa source dans une approbation jupitérienne de l'élu. L'auctoritas des sénateurs patriciens (puisque c'est à eux qu'était réservée la ratification des lois) leur venait d'une détention statutaire des auspices; ce privilège faisait aussi que la composante patricienne du sénat incarnait à elle seule le principe de continuité, seul élément de comparaison avec le fonctionnement d'un État, lorsqu'un interrègne laissait le pouvoir consulaire en vacance. Quant au peuple, son droit était originaire aussi en ce sens que les assemblées n'avaient d'autre justification, en dehors de la fondation romuléenne, que l'existence même de la cité, et qu'un même mot, populus, désignait à la fois l'assemblée comitiale et la totalité du corps politique (ce que Mommsen et la tradition allemande derrière lui appellent Staat, État). Dans un système qui ignore si délibérément l'intégration hiérarchique des compétences, l'homogénéité de la puissance publique et, pour tout dire, l'unité de l'État, on ne voit pas comment se représenter la souveraineté d'une manière positive. En revanche, une certaine manière d'unité et d'indivisibilité peut être pensée par le détour de l'inviolabilité. Le crimen maiestatis introduit l'idée d'une plénitude sinon de la puissance, du moins du périmètre où la loi l'enclave. Ce n'était pas encore la plénitude en acte d'une somme de compétences, telle que devait la concevoir le droit monarchique à la fin du Moyen Âge et au début de l'époque moderne. C'était une plénitude affirmée seulement comme intransgressible, à travers l'interdit. Lieu vide de la Majesté, qui projetait autour du pouvoir son cercle sanctuarisé.

L'histoire de l'État romain, si l'on veut entendre par ce mot autre chose qu'une vague approximation descriptive, c'est-à-dire si l'on veut comprendre dans les termes mêmes où elle fut formulée à Rome la problématique - et plus encore la pratique - de la construction juridique de l'Un, passe par le détour de l'histoire du crime de majesté. Le crime n'est pas un incident de parcours, une anomalie accidentelle. Il est au contraire l'événement que suppose l'institution politique édifiée sur la défense d'un point de référence ultime. Tout cela d'ailleurs est fort 
concret et doit se suivre à travers les voies effectives de la pratique judiciaire. Car l'histoire du pouvoir qui se réclame de la Majesté se confond pour l'essentiel avec l'histoire des procédures par lesquelles, dans le réel, celle-ci est mise à l'épreuve des faits.

Yan THomas, École des hautes études en sciences sociales. 